Received 00th January 20xx, Accepted 00th January 20xx DOI: $10.1039 / x 0 \times x 00000 x$

\section{New Analytical Tools for Advanced Mechanistic Studies in Catalysis: Photoionization and Photoelectron Photoion Coincidence Spectroscopy}

\author{
Patrick Hemberger, ${ }^{a *}$ Jeroen A. van Bokhoven, ${ }^{\mathrm{b}, \mathrm{c}}$ Javier Pérez-Ramírez ${ }^{\mathrm{c}}$ and Andras Bodi ${ }^{\mathrm{a}}$
}

\begin{abstract}
What are the reaction mechanisms responsible for the selective product formation in catalysis? How can we identify the reactive intermediates steering the reaction towards the desired reaction pathway? In this mini review, we explore novel in situ analysis techniques, such as photoionization and photoelectron photoion coincidence spectroscopy, to detect gas-phase reactive intermediates (radicals, carbenes, and ketenes) isomer-selectively. Mass spectrometry with tunable vacuum ultraviolet (VUV) synchrotron radiation is the first experimental approach to detect elusive species sensitively and selectively in catalytic oxidation reactions or the Fischer-Tropsch process. Further, we introduce a second analytical dimension, which utilizes imaging to enhance radical detection capabilities and provides strategies to address fragmentation in $\mathrm{C}-\mathrm{H}$ activation of alkanes. Thereafter, we present photoion mass-selected threshold photoelectron spectroscopy as the third analytical dimension revealing spectroscopic fingerprints to assign the elusive intermediates unequivocally and isomerselectively in lignin catalytic fast pyrolysis. Last, limitations and future perspectives are discussed.
\end{abstract}

\section{Introduction}

Catalysis is the key technology of our century to produce fine chemicals and transportation fuels in a clean and efficient manner, and is also widely used in exhaust gas aftertreatment. Catalysts increase the reaction rate by lowering the activation energy of the transition state along a reaction coordinate. Process conditions, such as pressure, temperature, concentration, or the nature of the catalyst are tuned to maximize the yield and selectivity of the desired product. Empirical "cook-and-look" approaches are often quite effective. However, it is the mechanistic understanding of the underlying

\footnotetext{
a. Laboratory for Synchrotron Radiation and Femtochemistry, Paul Scherrer Institute, CH-5232 Villigen PSI, Switzerland, patrick.hemberger@psi.ch

b. Laboratory for Catalysis and Sustainable Chemistry, Paul Scherrer Institute, CH5232 Villigen PSI, Switzerland

Institute for Chemical and Bioengineering, Department of Chemistry and Applied Biosciences, ETH Zurich, Zurich, Switzerland.
}

chemistry that provides the deepest insights and is highly desired for rational catalyst design and process optimization.

Reaction mechanisms are represented by reactive intermediates, i.e., metastable complexes, which are reached after passing through a transition state and correspond to local minima on the potential energy surface. While transition state lifetimes may only be in the order of femtoseconds, reactive intermediates can survive long enough to be present in sufficiently high concentrations to be detected. Thus, we can obtain direct evidence supporting a reaction mechanism if we can bring these elusive intermediates into the spotlight. But how can we achieve this?

The surface science approach at highly controlled conditions, e.g., reactions on single crystals, can provide mechanistic insights in model systems and elementary reactions in a vacuum environment. The results, however, may not be directly transferable to the practical arena because of the pressure and materials gaps between laboratory and process relevant conditions. Operando techniques bridge this gap by operating at working conditions at elevated pressures and temperatures: Nowadays, numerous methods exist to identify the surficial structural changes during catalyst operation, including microscopic and spectroscopic techniques. Structural changes of surfaces can be visualized with high pressure scanning probe microscopy. ${ }^{1,2}$ Near ambient pressure $\mathrm{x}$-ray photoelectron spectroscopy (NAPXPES) elucidates the oxidation state of the catalyst, the reactants, and the phase changes at close to operando conditions. ${ }^{3,} 4$ X-ray diffraction techniques are sensitive to probe surface properties and obtain crystallographic information of the atomic structure, i.e., the surface roughness or layer thickness. ${ }^{5} \mathrm{X}$-ray absorption and emission spectroscopies determine the active sites of a catalyst and the local electronic structure around the atom of interest.6, 7 The chemical structure of surface-bound species is revealed directly by in situ nuclear magnetic resonance (NMR) spectroscopy ${ }^{8}$ and Fourier-transform infrared (IR) spectroscopy. ${ }^{9}$

This document is the accepted manuscript version of the following article:

Hemberger, P., van Bokhoven, J. A., Pérez-Ramírez, J., \& Bodi, A. (2020). New analytical tools for advanced mechanistic studies in catalysis: photoionization and photoelectron photoion coincidence spectroscopy. Catalysis Science and Technology, 10(7), 1975-1990. https://doi.org/10.1039/c9cy02587a 


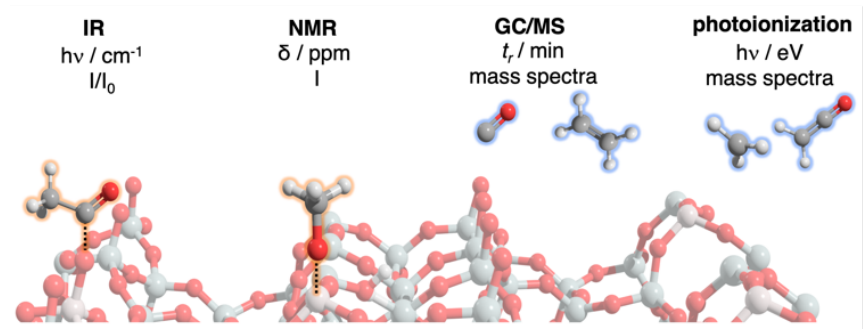

Figure 1. Surface intermediate characterization methods: NMR and IR spectroscopies detect surface acetate and methyl species in methanol-to-olefin processes. GC/MS is routinely performed to identify stable species in the gas phase. Photoionization mass spectrometry complements these by detecting short-lived species in the isolated phase.

Methanol (MTO) or syngas (STO) to olefin conversion is known to proceed by $\mathrm{C}-\mathrm{C}$ bond formation via elusive ketene intermediates. Ketene's role can be established indirectly by the addition of $D_{2} \mathrm{O}$ to the reaction mixture, which yields $d_{2}$-acetic acid. ${ }^{10}$ IR and NMR spectroscopies ${ }^{11}, 12$ identified surface acetate and methyl species on the catalyst (see Figure 1), providing insight into the reaction mechanism. However, the detection of intermediate species is difficult if their concentration is very low, if their spectral features overlap and if they are desorbed into the gas phase. Especially in the last case, detection is routinely performed via online gas chromatography and mass spectrometry (GC/MS). However, only stable species, such as $\mathrm{CO}$ and ethylene (Figure 1), can be detected in the MTO and STO processes, because reactive and elusive intermediates, such as radicals, carbenes and ketenes, do not survive sampling and evade detection.

In the last decade, a new set of techniques have emerged at third generation synchrotron facilities for the gas-phase detection of reactive intermediates in catalysis research. ${ }^{13-15}$ Their advantages are immediately obvious when part of the reaction mechanism takes place in the gas phase or when the goal is to distinguish surface-bound and gas-phase chemistry. However, even if the chemistry is entirely surface-bound weakly bound reactive intermediates may desorb and give valuable clues about the surface chemistry.

In this mini review, we cite examples for both as we discuss the sensitive, selective, and multiplexed detection of reactive intermediates in the gas phase at relevant conditions. We address these issues from the perspective of catalysis research: How can we extend the lifetime of elusive molecules to enable their detection? Why is mass spectrometry (MS) the most suitable technique? What are the pitfalls of radical detection? Upon answering these questions, we will introduce three analytical dimensions and show their value based on catalysis examples.

Ionization techniques are reviewed to introduce the first analytical dimension, namely the ionization energy in tunable vacuum ultraviolet (VUV) photoionization. Different enough ionization energies often enable the isomer-specific assignment of intermediates in photoionization mass spectrometry.

Next, velocity map imaging (VMI) is introduced as a second analytical dimension to optimize radical detection. VMI helps greatly to overcome sampling effects by visualizing the velocity components of the detected cations. Furthermore, it also provides a strategy to distinguish direct photoionization of an intermediate from dissociative ionization. The dissociation of a heavier cation yielding a fragment ion at the $\mathrm{m} / \mathrm{z}$ of interest is a typical complication in MS. If the detected fragment ion has the same molecular mass as a possible intermediate, a misinterpretation of mass spectrometric results may compromise the derived reaction mechanism.

Finally, photoelectron photoion coincidence (PEPICO) spectroscopy is introduced providing the third analytical dimension. The photoelectron spectrum, recorded for a single $\mathrm{m} / \mathrm{z}$ ion channel, reveals vibrational fingerprints used to distinguish isomers unequivocally and to increase the resolution and dynamic range of isomer-selective detection in photoionization mass spectrometry.

\section{1) Why mass spectrometry?}

The first requirement for detecting reactive intermediates in catalysis in the gas phase is a sensitive detection technique. In this section, we will discuss different techniques, their advantages, and their limitations in catalysis research.

Conventional absorption techniques, such as ultraviolet (UV) and infrared (IR) spectroscopies, require large concentrations (partial pressure) of the analyte, in the hundreds of part per million (ppm) range to measure a detectable extinction, $E_{\lambda}=$ $\log \left(I / I_{0}\right)$. Since reactive intermediates typically exhibit much smaller concentrations, this may call for long absorption path lengths, according to the Lambert-Beer law: ${ }^{16}$

$$
E_{\lambda}=\log \frac{I}{I_{0}}=\varepsilon_{\lambda} \cdot c \cdot d,
$$

where $\varepsilon_{\lambda}$ is the extinction coefficient, $d$ is the optical path length and $c$ is the concentration. Thus, low concentrations require long and uniform reactors with optical accessibility, or highly reflective mirrors to create ultralong path lengths, as in cavity ringdown spectroscopy, ${ }^{17}$ by which, e.g., Hemdal and Johansson investigated the oxidation of hydrogen on platinum catalysts to determine the temperature and concentration of $\bullet \mathrm{OH}$ radicals. ${ }^{18,19}$ Absorption techniques are rarely feasible to study complex systems, when side reactions such as coking are at play, since the transmission of windows may change. These shortcomings may be partially compensated by applying planar laser induced fluorescence (PLIF), which is a well-established technique in combustion diagnostics and capable of detecting reactive intermediates on a sub-ppm level. There are a few examples in catalysis research, which shed light on the role of - $\mathrm{OH}$ radicals ${ }^{20}$ or other reactive intermediates in the gas phase. ${ }^{21,} 22$ Apart from identifying reactive intermediates, PLIF was also used to identify carbon dioxide boundary layers, which dramatically changes the gas phase concentration close to the catalyst surface in carbon monoxide oxidation. ${ }^{23}$ The major drawbacks of these techniques are that they are neither selective if, e.g., fluorescence bands overlap nor universal if emission lines are unknown or even absent. In the absence of multiplexing capabilities, they are not able to detect all intermediates, but are tailored to one or just a few species. This means that relying exclusively on such methods may result in 
major reaction pathways being overlooked as was recently pointed out for the photochemistry of acetylacetone. ${ }^{24}$

Time-of-flight mass spectrometry (ToF-MS) overcomes most of these limitations as ionization and ion detection are universal. ToF-MS is mostly selective, as well, because reactants, intermediates and products can be distinguished according to their arrival times at the detector if their mass-to-charge $(\mathrm{m} / \mathrm{z})$ ratio is sufficiently different. MS detection is also sensitive and can easily reach part-per-billion ( $\mathrm{ppb}$ ) levels. The mass analysis takes place in a high vacuum environment, which raises the question of sampling interface and leads us to the next requirement to allow for sampling directly from a chemical reactor and transporting the unchanged mixture directly into the mass spectrometer.

\section{2) Molecular beam sampling to protect and detect reactive intermediates}
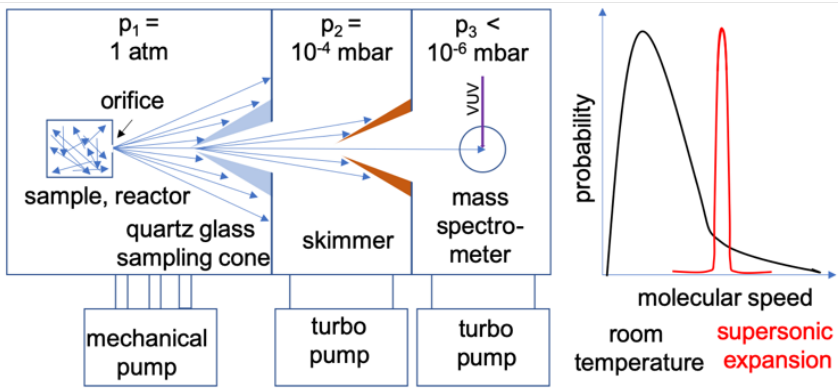

Figure 2. a) Schematic view of the molecular beam sampling technique. The catalytic reaction takes place in a reactor at one atmosphere. A quartz glass cone with a small orifice is used to probe a small portion, which is expanded into vacuum to form a molecular beam and skimmed in a second chamber. The beam travels with the speed of sound towards the ionization volume of the spectrometer. The translational degrees of freedom are efficiently cooled in the supersonic expansion and a narrow velocity distribution is formed along the molecular beam axis (right graph).

Molecular beam sampling (MBMS, Figure 2), can achieve these goals. First used by Kistiakowsky et al., ${ }^{25}$ it became a versatile tool for flame sampling ${ }^{26}$ and was later also applied in catalytic experiments, ${ }^{27}, 28$ coupled with electron ionization (EI). The sampling interface must bridge nine orders of magnitude of pressure difference when the reactor is operated at ambient conditions, requiring multi-stage differential pumping. The first, reactor vessel is at ambient pressure, and is placed in a vacuum chamber pumped by a mechanical pump. This chamber contains a sampling cone with a small nozzle, which interfaces it to a second vacuum chamber, pumped by a turbo molecular pump. The expansion into high vacuum $\left(10^{-4} \mathrm{mbar}\right)$ generates a molecular beam, where the internal degrees of freedom are collisionally cooled and the randomly oriented motion of the gas molecules are collimated in the beam propagation direction (Figure 2, left). Due to the dilution in a noble gas, reactive collisions are suppressed and unstable intermediates are preserved in the expansion.

The centerline of the expansion is sampled using a skimmer, and the species are transferred collision free to the ionization region. Thanks to the low number density in the high vacuum chamber the mean free path is above $1 \mathrm{~m}$. The acute angle of the sampling cone and the skimmer prevents backscattered gas from entering the apertures and thus only sample emanating directly from the reactor is sampled. Instead of the first highpressure vessel, a low-pressure (max. 100 mbar in the reaction zone) microreactor may be placed directly in the intermediate vacuum chamber. ${ }^{29,} 30$

\section{3) The first analytical dimension - ionization methods: Scalpel or sledgehammer}

In this chapter, we discuss different ionization techniques and identify the most versatile one with the help of two examples. Electron ionization (EI) relies on the interaction of an electron beam with the neutral sample to produce cations (see Figure 3a). This technique is very sensitive and widely used, but has some disadvantages. The electron energy is often so large that it induces significant fragmentation. Even when slow electrons are used, the ion signal may already be observed below the ionization energy due to the large energy spread of thermally produced electrons ( $\mathrm{fwhm}=1 \mathrm{eV}$, red Gaussian curve, Figure 3a). ${ }^{27}, 28,31$ This makes $\mathrm{El}$ an isomer-unselective detection method. Finally, fragmentation or dissociative ionization ( $R-H$ $\rightarrow \mathrm{R}^{+}+\mathrm{H}$, see Figure 3, left), occurs once the energy deposited in the parent ion is greater than its ionization limit. The lighter fragments produced can easily be falsely assigned to radical intermediates. El offers poor fragmentation control, making it a hard ionization tool unsuited to the analysis and assignment of complex reactive mixtures in the absence of extensive calibration data. In typical settings, El is the sledgehammer: a universal but rather unselective ionization tool.

A resonant transition into an excited neutral state is populated using a UV laser $\left(h v_{1}\right)$ before a second photon $\left(h v_{2}\right)$ ionizes the analyte in resonance enhanced multiphoton ionization (REMPI) (see Figure $3, \mathrm{~b}$ ). Optical parametric oscillators (OPA) and dye lasers are tunable and provide narrow-band radiation ( $\mathrm{fwhm}<$ $1 \mathrm{~cm}^{-1}$ or $100 \mu \mathrm{eV}$ ), resonant with transitions into an intermediate neutral state. Transitions strongly depend on the structure of the excited states and can thus be used as isomerspecific detection tool for larger molecules in catalysis, ${ }^{32}$ which makes tunable multiphoton laser ionization a highly selective approach. 
a)

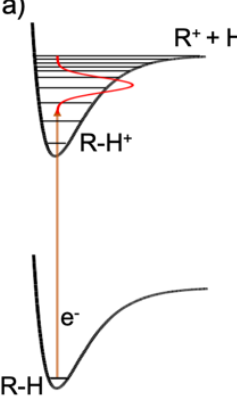

electron ionization multiphoton ionization

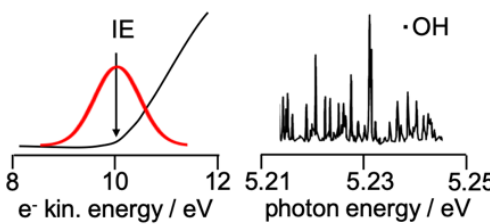

e- kin. energy / eV photon energy / eV c)

b)

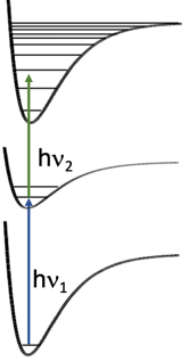

resonant enhanced

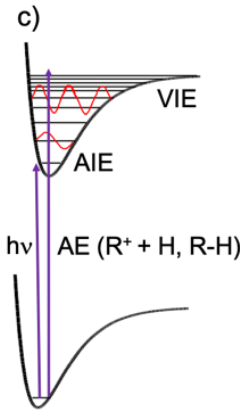

single photon ionization

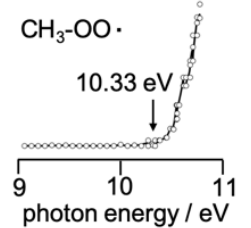

Figure 3 Different ionization methods used in mass spectrometric applications. While electron ionization a) (EI) is rather unselective due to the large energy spread, two-color resonant multiphoton ionization b) (REMPI) shows rovibrational lines, which are isomer specific but is limited by selection rules. Photoionization mass spectrometry is a universal technique, as single-photon photoionization (c, $\mathrm{SPI}$ ) is not limited by spectroscopic selection rules and ionizing transitions are always allowed above the ionization energy. Data points digitized from refs. ${ }^{33}$ and

Figure $3 b$ shows the REMPI spectrum of the $\bullet \mathrm{OH}$ radical, rich of fine structure, as produced upon catalytic oxidation of hydrogen. ${ }^{33}$ As REMPI relies on resonance enhancement, it is very sensitive with a detection limit of less than a part-pertrillion (ppt). ${ }^{35}$ It also offers state selectivity with respect to the rovibrational state of the neutral, which allowed Elg et al. to determine that $\bullet \mathrm{OH}$ radicals produced in catalytic water formation on a platinum polycrystalline foil and desorbed from the surface have a rovibrational temperature of $800 \mathrm{~K} .{ }^{33}$ Creighton et al. used REMPI to detect trace amounts of methyl radicals produced upon dissociative chemisorption of trimethylgallium on a GaAs (100) surface at temperatures as high as 713 K. ${ }^{36}$ However, REMPI techniques are limited by selection rules and the knowledge of the intermediate energy levels. Because of the resonance enhancement REMPI is not a universal detection tool but, similar to LIF and background-free four wave mixing ${ }^{37}$ schemes, is, like a scalpel, applicable for tailored and specialized questions rather than for resolving the composition of complex reactive systems.

Single photon ionization (SPI) is not limited by spectroscopic selection rules and ionizing transitions are always allowed above the ionization energy. Thus, SPI is not only sensitive (a single ion can be detected) and selective (according to $\mathrm{m} / \mathrm{z}$ and ionization energy), but also a truly universal detection method. ${ }^{38}$ Even without the benefit of resonance enhancement, the SPI detection limit can be lower than a part per billion (ppb). ${ }^{38,39}$

Valence ionization energies fall in the vacuum ultraviolet (VUV) energy range. VUV laser sources employ four wave mixing or high harmonic generation schemes and most laboratory-based sources are targeted at specific applications with limited

tunability or low average flux. ${ }^{40-42}$ Synchrotrons are quasicontinuous broadband light sources and easily tunable in combination with monochromators. Depending on the radiation source (bending magnet or insertion device), the gratings used and the design of the beamline, very high photon energy resolution (sub-meV) or high photon flux ( $>10^{14}$ photons $\mathrm{s}^{-1}$ ) can be reached. ${ }^{43-47}$ VUV photoionization mass spectrometry is, thus, a powerful analytical tool to detect gas phase species at synchrotron radiation sources.

The first analytical dimension we introduce is the photon energy dependence of the ion signal in a given $\mathrm{m} / \mathrm{z}$ channel of interest, namely the photoionization spectrum (PIS). At low photon energies $(<10 \mathrm{eV})$, reactive intermediates can be ionized selectively as, e.g., doublet radical species tend to have the lowest ionization energies. At a synchrotron, the photon energy can be tuned to above $15 \mathrm{eV}$ within seconds, at which energy even the most stable species, such as nitrogen, carbon monoxide, and carbon dioxide ionize, while organics undergo significant fragmentation. Thus, tunable photoionization can be a scalpel or a sledgehammer, depending on the experimental needs. In the PIS of a single species, the ion signal starts to rise at the adiabatic ionization energy. Figure $3 c$ (lower right) shows the PI spectrum of the $\mathrm{m} / \mathrm{z} 47 \mathrm{channel}$, with an signal onset at ca. $10.33 \mathrm{eV}$, measured during the oxidative coupling of methane over a $5.6 \%-\mathrm{Li} / \mathrm{MgO}$ catalyst. ${ }^{34} \mathrm{By}$ comparing this curve with ionization energy calculations and with reference spectra, ${ }^{48,49}$ the signal was assigned to the methylperoxy radical $\left(\mathrm{CH}_{3}-\mathrm{OO} \bullet\right)$. As seen in Figure 3c, upper right, all ion states are accessible below the photon energy with transition probabilities determined primarily by the overlap integral of the nuclear wave function of the neutral and the cation states, i.e., the Franck-Condon factor. Thus, the PIS monotonically increases above the ionization energy, and characteristically of the integral of Franck-Condon factors up to the given energy. ${ }^{31}$ Constitutional isomers usually have sufficiently different adiabatic ionization energies so that changes in the slope of the PIS can be associated with different isomeric contributions. We will cite two examples to show how this can be used in catalysis to distinguish isomers and isobaric (same nominal mass) species. ${ }^{50}$

\section{1) Partial oxidation of VOCs}

Acetaldehyde and ethenol (vinyl alcohol) are $\mathrm{C}_{2} \mathrm{H}_{4} \mathrm{O}$ isomers and can be distinguished based on their different ionization energies, which is mirrored by the different slopes of the PI curve as depicted in Figure 4 (upper trace). Ethenol exclusively ionizes at $9.33 \mathrm{eV}$, while acetaldehyde, its tautomer, is only observed at $10.21 \mathrm{eV}$. Ethenol was found in hydrocarbon flames as reactive and short-lived intermediate and hypothesized to play a key role in the partial oxidation mechanism of hydrocarbons and in pollutant formation. ${ }^{51}$ Triggered by the observation of enolic surface species during the partial oxidation of ethanol over $\mathrm{Ag} / \mathrm{Al}_{2} \mathrm{O}_{3}$, using diffuse reflectance infrared Fourier transform spectroscopy (DRIFTS), ${ }^{52} \mathrm{Li}$ et al. investigated the catalytic oxidation mechanism of alcohols using the same catalyst at NSRL in Hefei, China. ${ }^{53}$ Molecular 
beam sampling combined with photoionization mass spectrometry with vacuum ultraviolet synchrotron radiation showed strong pressure dependence of ethenol formation, as visible in the PI curves in Figure 4a. While at lower reactor pressures, both acetaldehyde (onset at $10.21 \mathrm{eV}$ ) and ethenol (onset at $9.33 \mathrm{eV}$ ) were detected, the latter species was absent at atmospheric pressure. Furthermore, dehydrogenation and dehydration of ethanol is favoured at reduced pressures to yield ethene and propenal. The observation of the reactive intermediates ketene and ethenol has led to the proposed mechanism in Figure $4 \mathrm{~b}$. Considering that the enolic anion $\left(\mathrm{CH}_{2}=\mathrm{CH}-\mathrm{O}\right)^{-} \mathrm{M}^{+}$intermediate has been observed on the catalyst surface in DRIFT measurements, 52 these findings suggest that they may be partially desorbed as ethenone into the gas phase.

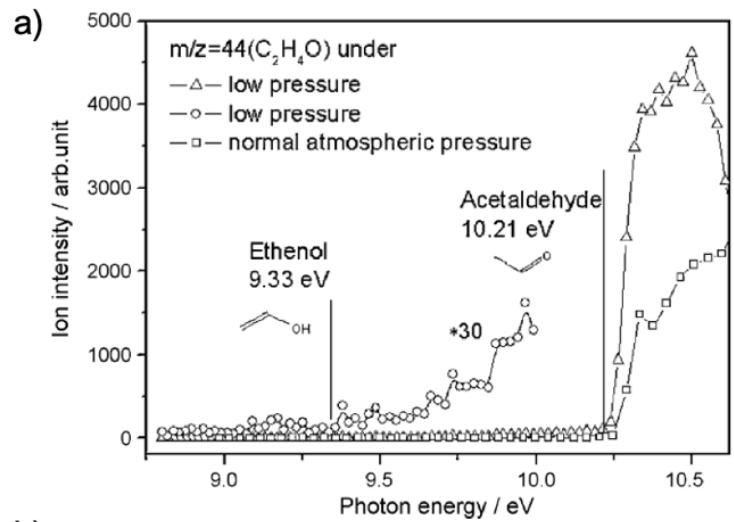

b)

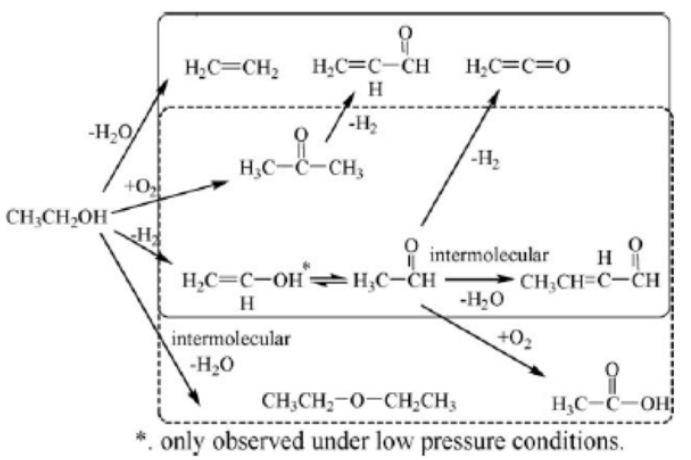

Figure 4. a) Photoionization spectra of $m / z 44\left(\mathrm{C}_{2} \mathrm{H}_{4} \mathrm{O}\right)$ at different reactor pressures during $\mathrm{Ag} / \mathrm{Al}_{2} \mathrm{O}_{3}$ catalyzed oxidation of ethanol. Ethenol can be clearly observed and distinguished from the acetaldehyde tautomer at low pressures, thanks to its lower ionization energy $(9.33 \mathrm{eV})$. The derived mechanistic aspects of ethanol oxidation are summarized b). Reprinted from ref ${ }^{53}$, Copyright (2009) with permission from Elsevier.

\section{2) Fischer-Tropsch synthesis}

The next example shows why a tunable light source is important together with high mass resolution: Ketene $\left(\mathrm{H}_{2} \mathrm{C}=\mathrm{C}=\mathrm{O}\right.$, ethenone) was experimentally detected by Jiao et al. as reactive intermediate during the conversion of $\mathrm{CO} / \mathrm{H}_{2}$ (syngas) to olefins utilizing a bifunctional catalyst $\left(\mathrm{ZnCrO}_{x} /\right.$ zeolites) at NSRL. ${ }^{54}$ They coupled a low-pressure (5-50 mbar) reactor to a high-resolution reflectron time-of-flight mass spectrometer. The isobaric propene and ketene, both produced in the Fischer-Tropsch synthesis process, have very close lying adiabatic ionization energies of $9.6191^{55}$ and $9.744 \mathrm{eV}^{56}$, respectively. Thanks to the tunable VUV radiation and the high mass resolution, they were able to selectively detect ketene at an exact mass of $m / z$ 42.01, which exclusively ionizes at $9.72 \mathrm{eV}$ (see Figure $5 \mathrm{~b}$ ).

Propene $(\mathrm{m} / \mathrm{z} 42.05)$, on the other hand, dominates the mass spectrum at $11.4 \mathrm{eV}$, at which photon energy the ketene $(\mathrm{m} / \mathrm{z}$ 42.01) contribution to the single $m / z 42$ peak is minute and far from baseline separated in the spectrum (mind the different scales of the ketene and propene signals in the inset of Fig. 5). Separation only becomes possible thanks to the tunabilty of the VUV radiation, even in the presence of hot band transitions of propene. The reaction mechanism can be summarized as follows: $\mathrm{CO}$ and $\mathrm{H}_{2}$ generate reactive $\mathrm{CH}_{2}$ on the metal oxide surface (see Figure 5 b). Methylene polymerization is hindered by reaction with abundant $\mathrm{CO}$ to produce gas-phase ketene. The latter diffuses from the metal oxide sites to the zeolite (bifunctional catalyst), where they selectively produce $C_{2}$ to $C_{4}$ olefins. The capability to detect ketene helped to elucidate the reaction mechanism of this process, and contributed to the overall understanding of the role ketenes play in catalysis. ${ }^{57}$

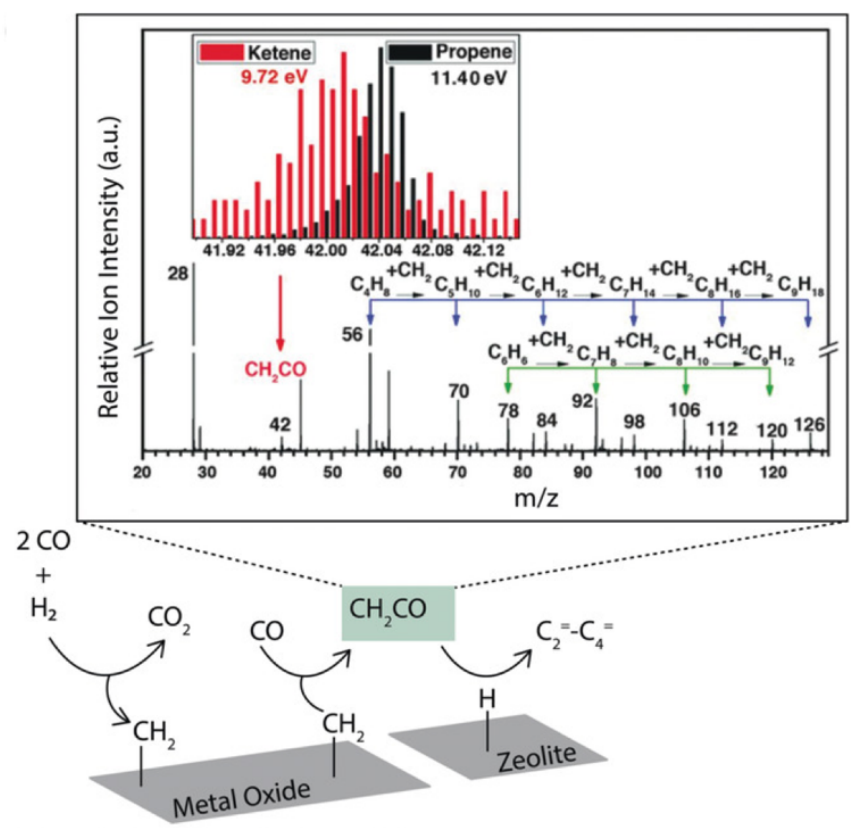

Figure 5. Photoionization mass spectrum taken during syngas conversion. The inset shows the contributions of ketene and propene, which dominate at 9.72 and $11.40 \mathrm{eV}$, respectively. The high mass resolution enables us to distinguish between these isobaric species. The lower trace shows the reaction mechanism based on the detection of ketene species, which are formed on the metal oxide catalyst, diffuse to the zeolite, and act as mild reactive intermediate to selectively produce $\mathrm{C}_{2}-\mathrm{C}_{4}$ olefins. Taken from references 57 and ${ }^{54}$. Reprinted (adapted) with permission from John Wiley and Sons and AAAS.

\section{4) The second analytical dimension: (velocity map) imaging}

As seen in the previous examples, VUV photoionization mass spectrometry is a powerful probe for reactive intermediates in catalysis. Although carefully chosen photon energies alleviate the issue of fragmentation compared with electron ionization, several questions remain unanswered: Can directly ionized 
radicals be distinguished from dissociative ionization of stable compounds when it is impractical or impossible to suppress dissociative photoionization of the latter by using low photon energies? Are there further sampling effects limiting the detection of reactive species? What is the fate of reactive intermediates in the detection chamber?

\subsection{Maximizing radical detection}

Stable reactants and products may be backscattered to the ionization region, while fleeting intermediates may be lost to wall collisions quantitatively. ${ }^{58}$ Depending on the alignment of the source and the pumping conditions, $10-75 \%$ of the ion signal can be due to re-thermalized sample, and wall losses can skew the observed signal intensities towards the stable species. Therefore, it is advantageous to be able to tell apart neutrals directly emanating from the reactor from thermal background. lon velocity map imaging (VMI) can answer these questions and is the second analytical dimension to validate and help the interpretation of catalytic experiments. ${ }^{15}$ As mentioned previously, when the effluent gas leaves the hot reactor, it expands into vacuum and forms a molecular beam (see Figure 2 ), which travels at (super)sonic speeds towards the ionization volume of the mass spectrometer. Thanks to collisional cooling in the adiabatic expansion and skimming the molecular beam to keep only the centerline component, the velocities perpendicular to the $\mathrm{MB}$ axis are low. Figure $6 \mathrm{~b}$ shows ion momentum images taken in methane oxybromination. Here, Paunovic et al. converted a mixture of methane, oxygen and $\mathrm{HBr}$ into methylbromide over vanadyl pyrophosphate, $(\mathrm{VO})_{2} \mathrm{P}_{2} \mathrm{O}_{7}$ (see Figure 6a). The reactor was part of the molecular beam setup of the photoelectron photoion coincidence (PEPICO) endstation, ${ }^{44,59}$ which is equipped with a velocity map imaging detector, ${ }^{60}$ at the VUV beamline of the Swiss Light Source. ${ }^{45}$

In VMI, particles are focused onto concentric rings according to their momentum in the image plane. The higher the momentum, the larger the distance from the center of the detector. In oxybromination, methyl (blue dots, Figure 6b) and bromine (red dots, Figure 6) radicals are produced in the reactor, have a large velocity along the molecular beam axis and a narrow speed distribution perpendicular to it. Although the molecular beam flies into a high vacuum pump, parts of it will inevitably be reflected on the electrodes, the magnetic shielding or the vacuum chamber walls. These species rethermalize and exhibit a room temperature (RT) velocity distribution, which appears as a large spot in the center of the detector (see Figure $6 \mathrm{~b}$, yellow RT background). Since the molecular beam is shifted away from the center of the detector because of its high velocity, the molecular beam and RT background signals are separated and species emanating directly from the reactor can be unambiguously identified as such. In contrast to conventional molecular beam mass spectrometry, VMI enables a direct visualization of the beam quality by $2 \mathrm{D}$ images. Sampling effects, which result from a misaligned molecular beam, limiting the detection sensitivity towards reactive molecules, can thus largely be avoided. Thanks to this sensitivity increase, Paunovic et al. could shed light on the mechanism of the oxybromination of methane. Bromine radicals and molecular bromine are generated on the catalyst surface, followed by a radical driven bromination of methane in the gas phase to yield methyl radicals. This is enabled by high concentrations of the reactants in the reactor, which leads to numerous radical reactions over the catalyst surface. These findings emphasize the role of surface and gas-phase steps in halogen-mediated $\mathrm{C}-\mathrm{H}$ bond activation, further corroborated by density functional theory calculations. ${ }^{15,61}$
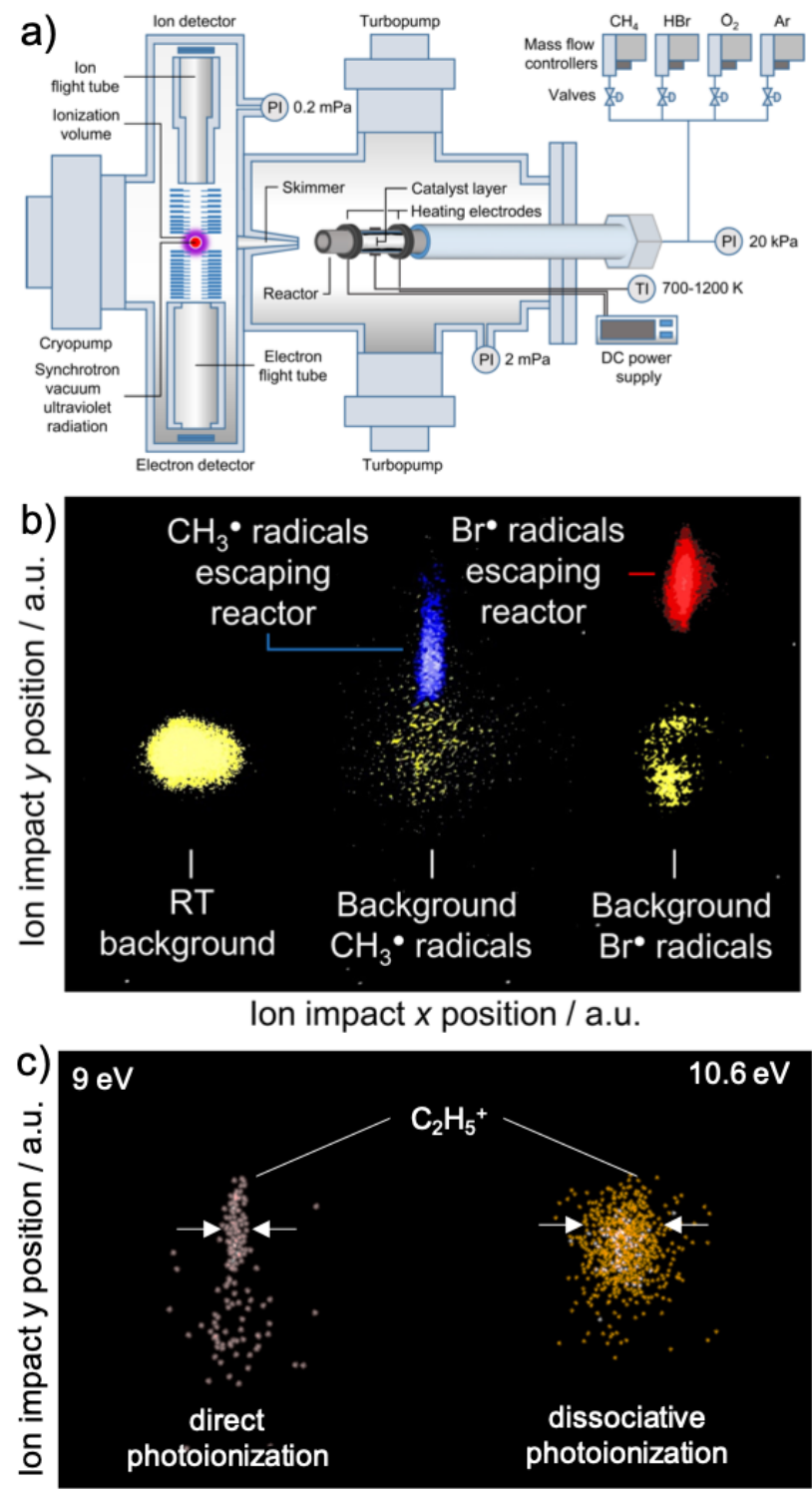

lon impact $x$ position / a.u.

Figure 6. a) Experimental setup at the VUV beamline of the Swiss Light Source: A low-pressure catalysis reactor is coupled to a molecular beam endstation to investigate oxyhalogenation reactions. Ions are detected in delayed coincidence with photoelectrons using a delay-line VMI detector. Ion momentum images in b) show a narrow velocity distribution of methyl and bromine radicals perpendicular to the molecular beam. This enables the optimization of the molecular beam alignment to minimize sampling effects and maximize the sensitivity to unstable species. c) VMIs of $\mathrm{C}_{2} \mathrm{H}_{5}{ }^{+}$at 9 and $10.6 \mathrm{eV}$. Directly ionized radical possess a narrow velocity distribution perpendicular to the molecular beam axis. Part of the excess energy is release as kinetic energy in the dissociative ionization of $\mathrm{C}_{2} \mathrm{H}_{5} \mathrm{Br}$ to yield $\mathrm{C}_{2} \mathrm{H}_{5}{ }^{+}$. This results in a broad velocity distribution. Reprinted (adapted) with permission from Springer from ref ${ }^{15}$ 
More recently, Zichittella et al. investigated the ethane functionalization by oxyhalogenation over iron phosphate, utilizing the same technique and found that the reaction mechanism strongly depends on the used hydrogen halide. They demonstrated that the superior selectivity to ethylene in oxychlorination is a direct consequence of a surface-confined reaction. ${ }^{62}$ Oxybromination, on the other hand, is a combination of surface chemistry to produce bromine radicals, leading to a bromination as well as numerous side reactions including cracking and yielding the combustion products $\mathrm{CO}_{2}$, water, and CO.62 These non-selective side reactions, were also observed upon $\mathrm{C}-\mathrm{H}$ activation of propane over $\mathrm{CrPO}_{4}$, in which 2-propyl, allyl and propargyl radicals were isomer-selectively detected. ${ }^{63}$ Early coke formation intermediates such as fulvene and benzene were observed and important mechanistic insight into these reactions could be obtained.

\subsection{Handling fragmentation}

The incident photon beam can dissociatively photoionize the sample to fragments with the same molecular mass as the radical species of interest. These hampers the direct radical detection and the following examples will show how this can be addressed.

Recently, Luo et al. have investigated the oxidative coupling of methane over $\mathrm{Li} / \mathrm{MgO}$ and observed $\mathrm{C}_{2} \mathrm{H}_{5}{ }^{+}$cations at the National Synchrotron Radiation Laboratory in Hefei, China. ${ }^{34}$ Their obtained PI spectrum shows a signal onset at $9.87 \mathrm{eV}$, however the ethyl radical exhibits a much lower ionization energy at around $8.35 \mathrm{eV}$ (see 1). They concluded that the ethylperoxy $\left(\mathrm{C}_{2} \mathrm{H}_{5}-\mathrm{OO} \bullet, \mathrm{m} / z 61\right)$ radical, which does not have a stable parent ion, contributes to the $\mathrm{m} / \mathrm{z} 29$ mass channel and could thus prove that peroxy species play a role in the OCM reaction mechanism, and are indirectly detected via reaction 2. 48

$\begin{array}{lll}\mathrm{C}_{2} \mathrm{H}_{5} \bullet+h v & \rightarrow & \mathrm{C}_{2} \mathrm{H}_{5}+ \\ \mathrm{C}_{2} \mathrm{H}_{5}-\mathrm{O}_{2}+h v & \rightarrow & \mathrm{C}_{2} \mathrm{H}_{5}^{+}+\mathrm{e}^{-} \\ & & \mathrm{e}^{-}+\mathrm{O}_{2}\end{array}$

$\mathrm{C}_{2} \mathrm{H}_{5}-\mathrm{O}_{2}+h v$ Upon replacing methane by ethane (oxidative
dehydrogenation, ODHE) they could indeed detect ethyl radicals based on the $\mathrm{PI}$ curve with an onset at $8.35 \mathrm{eV}$. Furthermore, in their apparatus, they can distinguish between surface (primary) and gas phase (secondary) processes by changing the distance of the sampling interface to the catalyst. Thanks to this feature, they concluded that in the ODHE reaction the gas phase contribution of ethyl to ethylene is less as compared to OCM. ${ }^{34}$

In 2004, Horn et al. investigated the catalytic formation of $\mathrm{HCN}$ from methane and ammonia over Pt with MBMS with coarsely tunable El threshold ionization. They identified methylenimine $\left(\mathrm{H}_{2} \mathrm{C}=\mathrm{NH}\right)$ as reactive species and could exclude the formation of methyl $\left(\mathrm{CH}_{3}\right)$ and imidogen $(\mathrm{NH})$ radicals as their onsets were clearly shifted to higher appearance potentials indicative for fragmentation rather than direct ionization. The two examples from Luo and Horn show that it is important to have tunability to distinguish directly ionized species from dissociatively ionized ones. Apart from minimizing sampling effects and the distinction of background gas from the reactor sample, velocity map imaging is also an excellent tool to visualize fragmentation processes even at a single photon energy. Upon fragmentation, the excess energy is statically redistributed, partially as translational energy of the fragments. ${ }^{64}$ This leads to a broadening of the narrow speed distributions perpendicular to the molecular beam axis. Figure $6 \mathrm{c}$ shows ion images for $\mathrm{m} / \mathrm{z} 29$ $\left(\mathrm{C}_{2} \mathrm{H}_{5}{ }^{+}\right)$from oxybromination of ethane over iron phosphate. ${ }^{62}$ While ethyl radicals are directly ionized at $9 \mathrm{eV}(\mathbf{1})$ and show a narrow speed distribution, dissociative ionization of ethylbromide to the ethyl cation (3) dominates at $10.6 \mathrm{eV}$ and kinetic energy release is evident in the ion image as broadening perpendicular to the beam axis.

$$
\mathrm{C}_{2} \mathrm{H}_{5} \mathrm{Br}+h v \quad \rightarrow \quad \mathrm{C}_{2} \mathrm{H}_{5}{ }^{+}+\mathrm{e}^{-}+\mathrm{Br}
$$

At first glance, this appears to be at odds with the tabulated appearance energy of $\mathrm{C}_{2} \mathrm{H}_{5}{ }^{+}$from ethylbromide at $11.21 \pm 0.05$ eV.65 However, the initial internal energy of neutral ethylbromide is high due to heating in the reactor and is also available for fragmentation. In such cases and despite cooling in the adiabatic expansion, apparent dissociative ionization onsets can red-shift by more than $700 \mathrm{meV}$, as previously pointed out by Baer, Sztaray or Vasilisou. ${ }^{66-69}$ Therefore, tabulated $0 \mathrm{~K}$ and RT dissociative photoionization onset energies may be misleading, especially if loosely bound species, such as halogenated hydrocarbons are studied, because fragmentation sets in at lower energies in hot samples. Since dissociative ionization measurements are temperature dependent and because of the differing contact time and heat transfer in the microreactor with or without catalyst, a blank ethyl bromide calibration measurement at the exact same conditions is hardly possible. Consequently, ion imaging can contribute to unequivocal sample assignment when sampling reactive intermediates from hot sources.

\section{5) The third analytical dimension: electron spectroscopy for isomer-selective detection}

As seen chapter 3 by the example of ethenol and acetaldehyde (Figure 4),53 photoionization spectra enable isomer-selective assignment if the isomer ionization energies are sufficiently different. However, in bigger systems, a plethora of possible isomers can often be postulated with close-lying ionization onsets. In such cases, photoionization curves have limited selectivity, due to the lack of fine structure. This becomes evident in Figure 7a, which shows photoionization curves (PI signal, blue) of ortho- and para-xylylenes produced in a pyrolysis ${ }^{29}$ reactor from stable precursors. ${ }^{70-72}$ Ortho- and paraxylylene show a very similar onset of the PI signal, making their assignment based on photoionization spectra inadequate. Spectral selectivity is restored by imaging photoelectron 


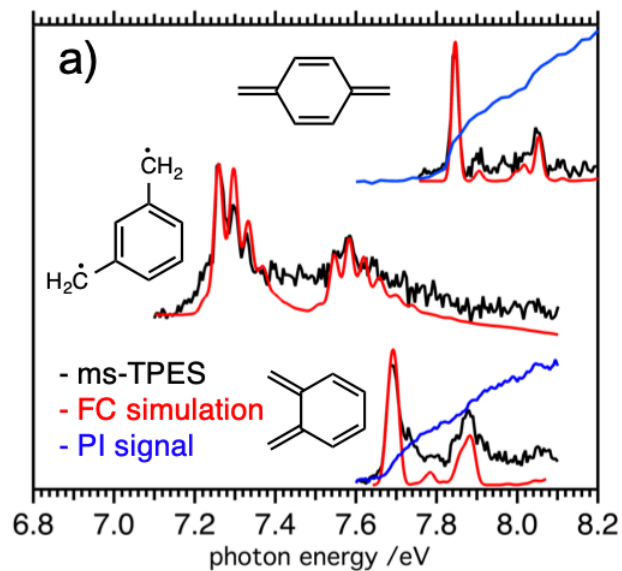

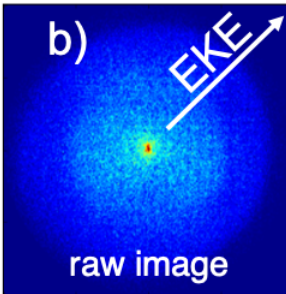
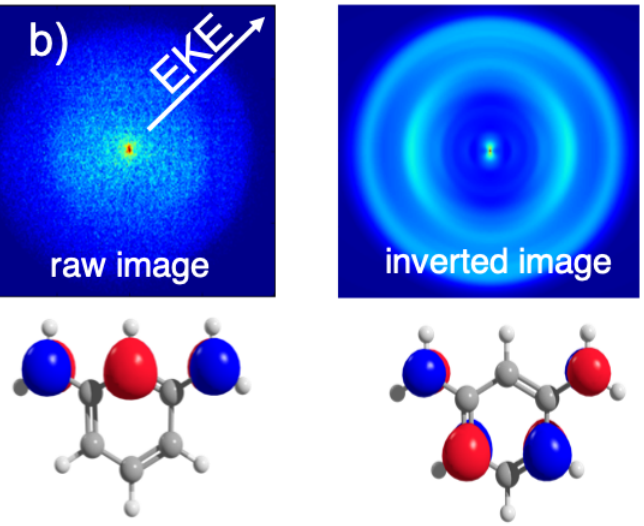

HOMO-1

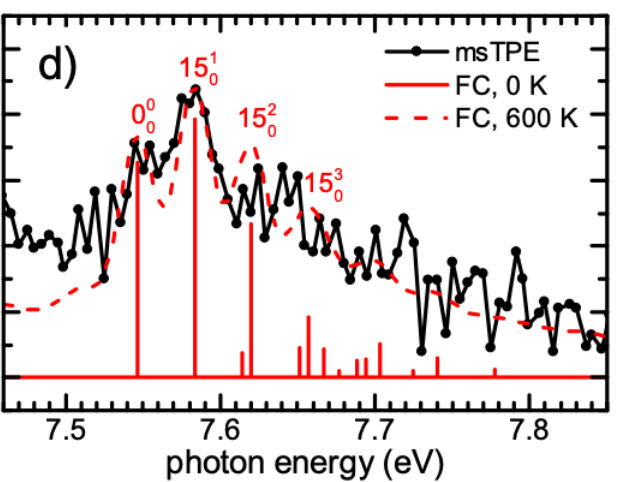

spectroscopic dimension determined by vibrational progressions from the neutral into the ion (see Figure 3c). The TPES is a much more sensitive probe of the sample structure than the PIS and is less susceptible to experimental conditions, meaning that it is easier to compare with reference data. ${ }^{73}$ Furthermore, FC factors can be routinely calculated in the double harmonic approximation, and can reliably aid the interpretation and assignment of even crowded spectra. ${ }^{74}$ No comparable approaches exist for the interpretation of $\mathrm{PI}$ spectra, which explains why iPEPICO provides superior isomerselectivity for reactive intermediates in pyrolysis studies, ${ }^{75,} 76$ flame sampling, ${ }^{77,} 78$ kinetic experiments, ${ }^{79}$ and, more recently, also in catalysis. ${ }^{14,15,61,62}$ Figure 7a shows ms-TPE spectra of the three xylylene isomers together with FC simulations in excellent agreement. In case of the meta-derivative, a very reactive biradical species, we observe activity of a totally symmetric methylene bending vibration $\left(v_{15}\right)$ and a ring breathing mode $\left(v_{14}\right.$, Figure $\left.7 c\right)$ as expected when removing an electron from the highest occupied molecular orbital (HOMO, in Figure 7) to form the cation ground state. ${ }^{72}$ At $7.58 \mathrm{eV}$, the first excited ion state is accessible, in which an electron is removed from the second least stable orbital, the HOMO-1 (see Figure 7). ${ }^{80}$ Again, a methylene bending vibration $\left(v_{15}\right)$ is active upon populating the excited cation state of the biradical (Figure 7d). As these are vibrational transitions, the isomer-specificity of ms-TPES is similar to that of IR spectroscopy and the transitions can also be computed using standard quantum chemical approaches. Excellent agreement with excited electronic state calculations and $\mathrm{FC}$ simulations are also common. ${ }^{72,}{ }^{74}$ The velocity map 
electron images add a further layer of experimental information. Electrons are only imaged according to their inplane momenta in the raw images, but the 3D momentum distribution can be reconstructed to obtain the kinetic energy distribution as well as the angular distribution as a function of energy. ${ }^{81}$ In meta-xylylene, the angular distribution of the lowenergy ring (i.e., high-energy ion state) is anisotropic, and more electrons are emitted perpendicular to the polarization vector of the light (i.e., the $\beta$ parameter is slightly negative, see Figure $7 b)$. The high-energy ring, corresponding to the ground electronic state, is angularly isotropic and, thus, clearly belongs to a different electronic state. In combination with calculated ionization energies and FC simulations, PEPICO data can provide definitive, isomer-selective assignment of reactive intermediates. In the past decade this approach has been tested for a large set of different reactive intermediates ranging from smaller reactive species, such as methyl, ${ }^{75}$ amidogen, ${ }^{82}$ the Crigee intermediate, 83 propargylic, ${ }^{84,85}$ and allylic ${ }^{79,84,86}$ species up to medium-sized benzylic, ${ }^{70,87}$ picolyl, $^{88}$ and even anilino ${ }^{89}$ radicals. In the following, we will briefly review how the selectivity and universality of ms-TPE spectroscopy offered mechanistic insights into catalytic lignin valorization approaches at the VUV beamline of the Swiss Light Source.

\subsection{Decomposition of lignin model compounds}

These novel analytical dimensions become very important when separating isobaric and isomeric species in complex reactive systems depending on process conditions. In general, catalytic fast pyrolysis of biomass is a promising approach to produce platform chemicals, pharmaceuticals, and fuels for internal combustion engines with a neutral $\mathrm{CO}_{2}$ footprint. The CFP of lignin, one of the major, yet largely unvalorized, ingredients in biomass, is an ideal testbed to benefit from the isomer-selective detection capabilities of imaging PEPICO, because a multitude of reactive intermediates are expected to appear. Lignin is an over-functionalised macromolecule consisting of differently substituted benzene ring moieties. In the first step, lignin depolymerization takes place to phenolic subunits, such as benzenediols and guaiacol (2methoxyphenol). In the second step, the primary pyrolysis products are catalytically deoxygenated over zeolite catalysts to yield phenols and other aromatics..$^{90}$ Despite the economic and environmental potential, the few pilot plants ever commissioned had to shut down due the low selectivities and conversion achieved. ${ }^{91}$ Thus, a full mechanistic understanding of the gas phase and surface chemistry is arguably important to make CFP viable.

The unimolecular chemistry of the lignin model compounds benzaldehyde ${ }^{92}$, phenol, ${ }^{93}$ guaiacol, ${ }^{76,}{ }^{94}$ dimethoxybenzene, ${ }^{95}$ salicylaldehyde, 4-phenoxyphenol, 2-methoxyphenoxybenzene ${ }^{96}$ and catechol97 (Figure 8c) has been investigated using microreactors ${ }^{29}, 30$ with PIMS and PEPICO detection. The chemistry of especially the three benzenediols shows strong isomer-dependence. Upon deoxygenation, the
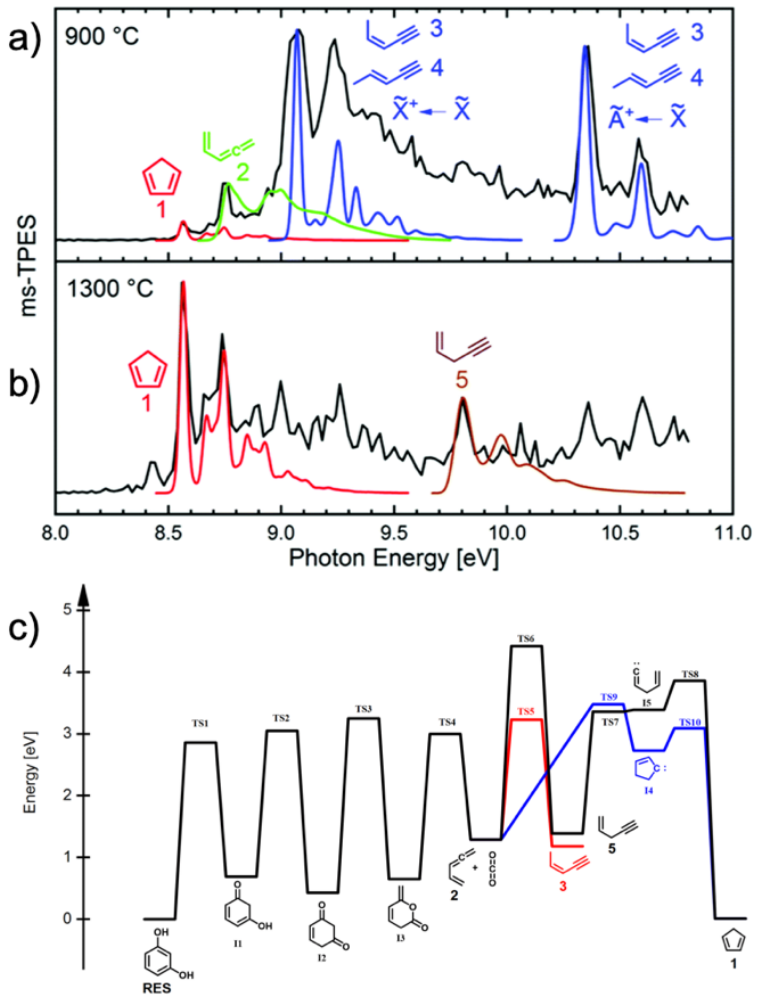

Figure 8. a) ms-TPES of $m / z 66$ taken at different reactor temperatures during the resorcinol decomposition in a micro reactor. Upon $\mathrm{CO}_{2}$ loss several $\mathrm{C}_{5} \mathrm{H}_{6}$ isomers are formed at different reactor temperatures (a) and (b), as identified based on their TPES. The potential energy surface $c$ ) for the decarboxylation mechanism could be calculated based on the experimental insights. Reproduced (adapted) with permission from ref ${ }^{98}$.

meta isomer resorcinol is the only one to lose $\mathrm{CO}_{2}$. The counter product was hypothesized to be cyclopentadiene ${ }^{97}$ or a $\mathrm{C}_{5} \mathrm{H}_{4}$ species. ${ }^{99}$ Only recently could Gerlach et al. show conclusively using PEPICO detection ${ }^{98}$ that resorcinol decarboxylation proceeds over acyclic $\mathrm{C}_{5} \mathrm{H}_{6}$ species, such as 1,2,4-pentatriene, $E$ and Z-1-butyne-3-ene, and 1-butyne-4-ene at moderate reactor temperatures (Figure 8a). Franck-Condon spectral modelling and high-level adiabatic ionization energy calculations yielded a definitive assignment of the $\mathrm{C}_{5} \mathrm{H}_{6}$ isomers. Cyclopentadiene dominates the ms-TPES only at elevated reactor temperatures, and its isomer-selective detection shows how the mechanism changes as a function of temperature (Figure 8b). PEPICO detection can thus identify varying isomeric contributions when process conditions are changed. These results can guide the exploration of the potential energy surface driving the resorcinol decarboxylation mechanism, which is depicted in (Figure 8c. Apart from the decarboxylation two ketene species, ethenone and 1,3-butadienal are uniquely formed from resorcinol as compared to catechol and hydroquinone thanks to the detection capabilities of PEPICO. 


\subsection{Guaiacol catalytic fast pyrolysis}

Naturally, catalytic surface reactions represent added complexity when compared with the unimolecular decomposition of resorcinol. Nevertheless, we could unveil the conversion mechanism of guaiacol, a lignin model compound, to prototypical fuels and fine chemicals, such as phenol and benzene, over HUSY, a zeolitic catalyst, using PEPICO (Figure 9a) and a temporal analysis of products (TAP)100, 101 type reactor. Guaiacol was highly diluted to less than 1:2000 in argon and pulsed over a HUSY catalyst coated quartz glass reactor, held at 650-750 K, which enabled us to restrict the reactions to the catalyst surface, while reactions in the gas phase are supressed. ${ }^{14}$

We relied on control experiments to choose reaction conditions carefully and analysed the complete threshold photoionization matrix (TPM, Figure 10). In the TPM, near-zero kinetic energy electrons signal is plotted as a function of the coincident ion $\mathrm{m} / \mathrm{z}$ and VUV photon energy. The columns of the TPM contain the photoion mass-selected threshold photoelectron spectra, and TPM analysis allows us to consider the entirety of the analytical data simultaneously. Stable reaction products, such as phenol ( $m / z$ 94), catechol ( $m / z 110)$, cresols $(m / z 108)$, and xylenols $(m / z$ 122), were identified based on their known photoelectron spectrum. The minor signal at $\mathrm{m} / \mathrm{z} 94$ below the IE of phenol is attributed to six possible isomers of dimethylcyclopentadiene, of which the calculated AIEs fall into the observed energy range. While $\mathrm{m} / \mathrm{z} 66$ and 80 were assigned to cyclopentadiene and methylcyclopentadiene (Figure 10a,c), $\mathrm{m} / \mathrm{z} 78$ and 92 (Figure $10 \mathrm{~b}, \mathrm{~d})$ were not so obvious, because the ms-TPES exhibited major contributions beyond those of benzene and toluene, respectively. In fact, ionization into the ground and excited ion states of fulvene dominated the $\mathrm{m} / \mathrm{z} 78 \mathrm{~ms}$-TPES and benzene was only a minor product as evidenced by the small peak at 9.24 eV. The $\mathrm{m} / \mathrm{z} 92 \mathrm{~ms}$-TPES showed a fundamental transition located at $8.25 \mathrm{eV}$ accompanied by a second broad band centered at around $8.4 \mathrm{eV}$, which was assigned to fulvenone (c$\mathrm{C}_{5} \mathrm{H}_{4}=\mathrm{C}=\mathrm{O}$, Figure 10d), a highly reactive ketene species, with the help of a Franck-Condon simulation. EOM-IP-CCSD calculations revealed that an electronically excited cation state is responsible for the high energy part of the ms-TPE above 8.6 $\mathrm{eV}$, which was not accounted for by the simulation. However, the contribution of further isomers and isobars could be ruled out, as their simulated spectra did not reproduce this featureless excited-state band.

In the py-PEPICO setup, the catalytic reactor is directly coupled to the ionization chamber at high vacuum and operated in the pulsed mode. The overall concentration of the reactant on the catalyst is thus very small and the average pressure is below 0.5 mbar. By suppressing collisional deactivation in the gas phase, thanks to the low pressure and the large sample dilution, reactive intermediates are preserved and can be detected using PEPICO. In contrast to the PEPICO data, ambient pressure pyrolysis GC/MS (py-GC/MS), reactive intermediates are absent primarily due to quenching in the long GC sampling line. ${ }^{14}$ Phenol, benzene, and methylated derivatives, notably cresols, are the major reaction products and observed in both environments (py-GC/MS and py-PEPICO).
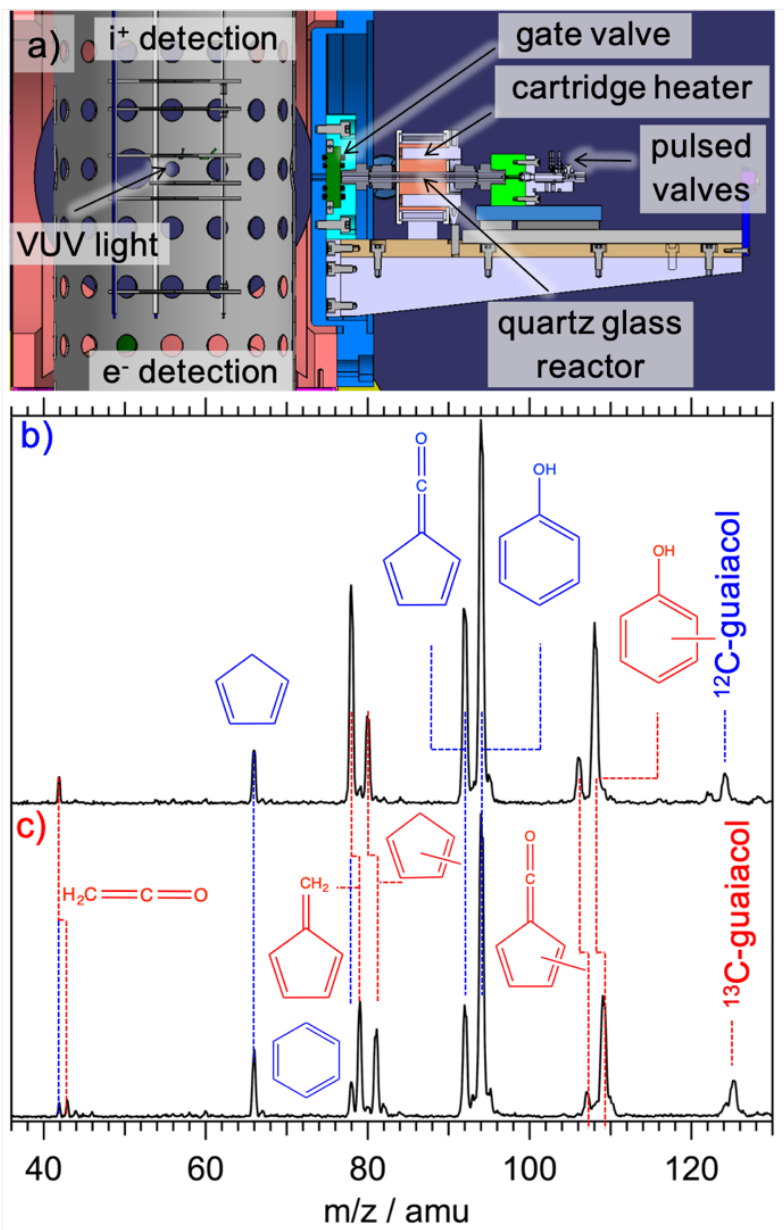

Figure 9 a) A temporal analysis of products (TAP) type py-PEPICO endstation at the Swiss Light Source. b) and c) show mass spectra of unlabelled and ${ }^{13} \mathrm{C}$-labled guaiacol. A unit $\mathrm{m} / \mathrm{z}$ shift takes place upon transmethylation, indicative of a Brønsted acid catalyzed process on the catalyst surface. Reproduced (adapted) from ref ${ }^{14}$. 

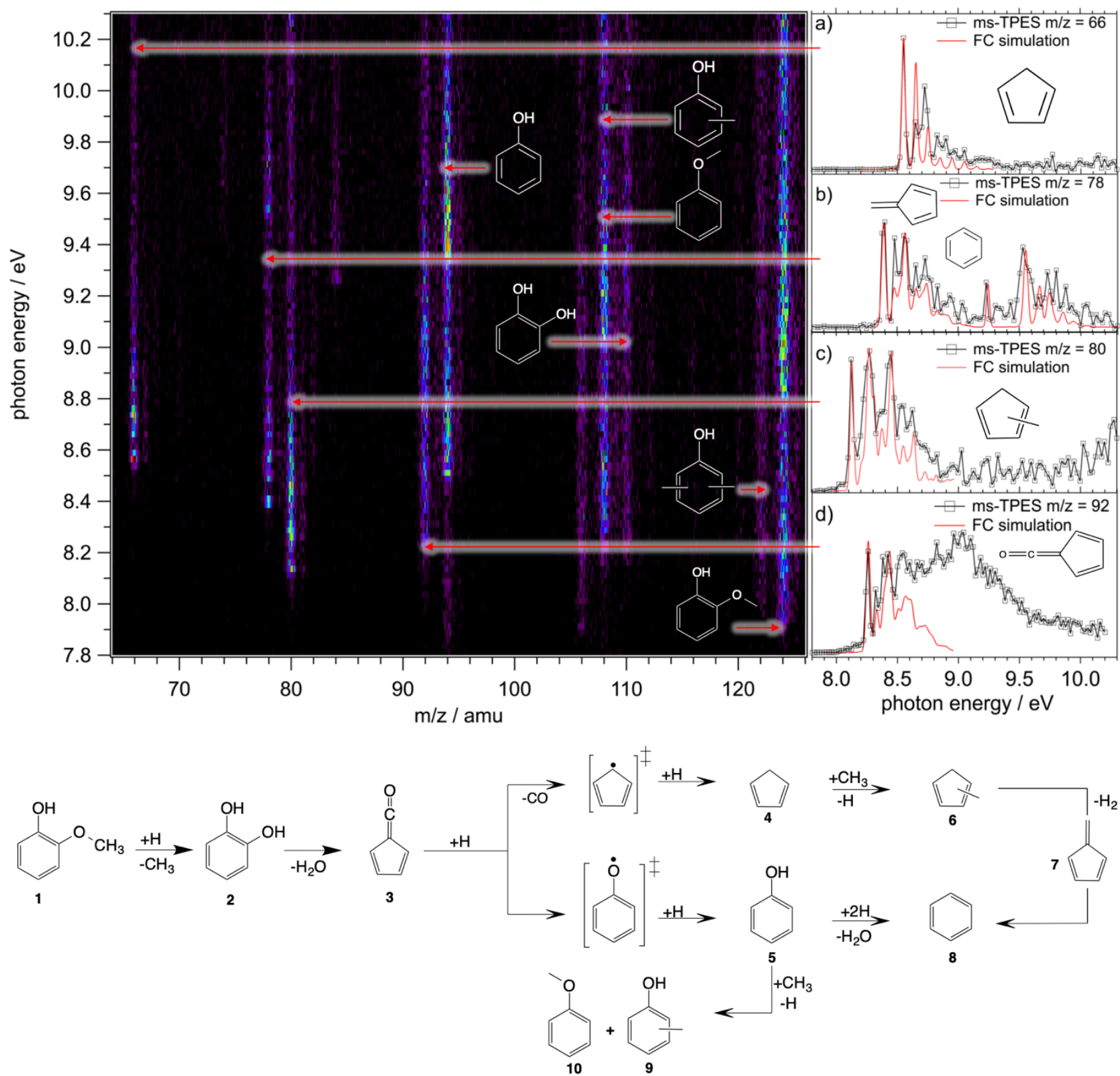

Figure 10 Threshold photoionization matrix (TPM) taken during the CFP of guaiacol over HUSY (upper trace). Fulvene and fulvenone ketene are assigned for the first time, and the latter species is found to be the central reactive intermediate in the CFP mechanism to form phenol and benzene (lower trace). Reproduced from ref ${ }^{14}$

Furthermore, we ${ }^{13} \mathrm{C}$-labeled the methyl group to follow its fate (see Figure 9a,b) and selectively turned off the transmethylation by utilizing catechol as reactant. Substituting the protons on USY with sodium ion suppressed the transmethylation and revealed desorbed radical species. These reference experiments have led us to the following mechanism: guaiacol $\mathbf{1}$ is demethylated in a Brønsted acid catalyzed reaction to yield catechol 2, which is subsequently dehydrated in a similar fashion to fulvenone $\mathbf{3}$ (see bottom part of Figure 10). 97 Selective methyl ${ }^{13} \mathrm{C}$-labeling of guaiacol (Figure $9 \mathrm{~b}$ and $\mathrm{c}$ ) cyclopentadiene $\mathbf{4}$ yields cresols $\mathbf{9}$ and methyl-cyclopentadienes 6. Fulvenone always remains unlabelled and is thus generated by removal of the labelled methyl carbon from guaiacol. It is therefore the central reactive intermediate in the transmethylation-driven CFP of guaiacol, which may also react with the abundant coke (see bottom of Figure 10) in hydride or hydrogen transfer steps to produce phenoxy and cyclopentadienyl radicals. These are strongly bound to the surface and react rapidly to phenol $\mathbf{5}$ and cyclopentadiene $\mathbf{4}$. Transmethylation leads to cresols $\mathbf{9}$, anisole $\mathbf{1 0}$ and methylcyclopentadiene $\mathbf{6}$, which can also dehydrogenate to yield fulvene $\mathbf{7}$ and ultimately rearranges to benzene $\mathbf{8}$. This example shows how even complex surface catalyzed reactions can be disentangled using advanced techniques like PEPICO.

resulted in a unit $\mathrm{m} / \mathrm{z}$ shift for the methylated products. Therefore, in the next step, transmethylation of phenol $\mathbf{5}$ and 


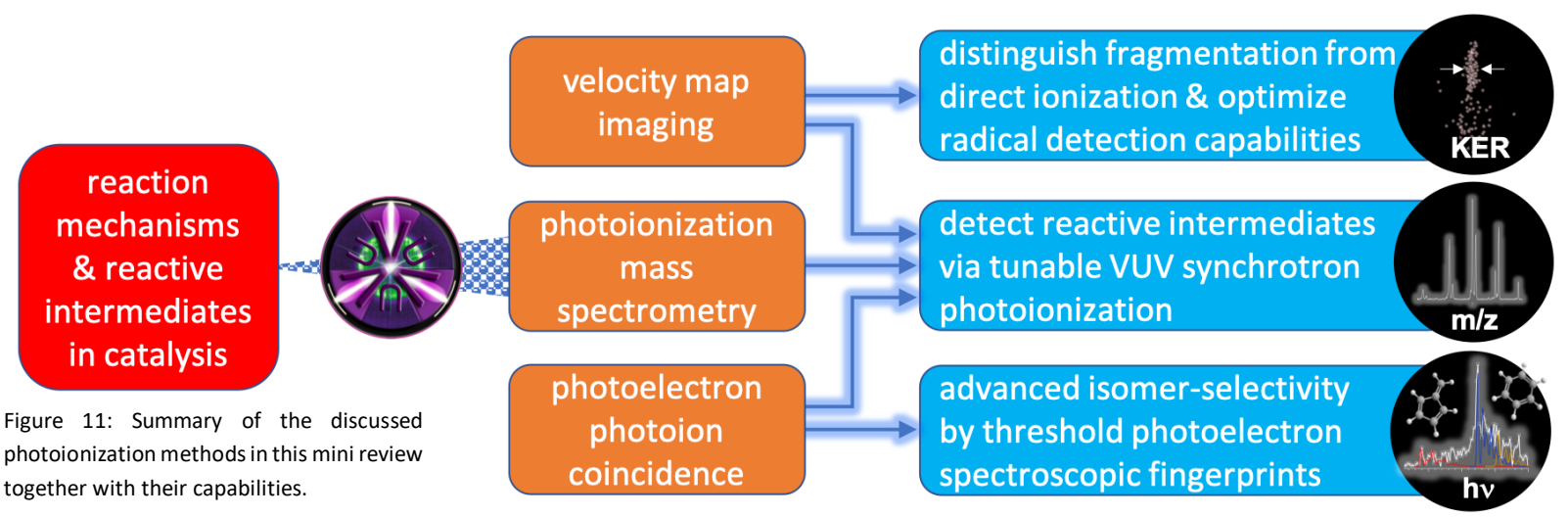

\section{6) Outlook - Pushing the limits}

\section{1) Sticky surfaces}

Reactive intermediates can be detected in the gas phase sensitively and (isomer-)selectively using MS and PEPICO with tunable VUV synchrotron radiation. If gas phase chemistry determines (part of) the mechanism, the reactants, intermediates, and products can all be detected and identified. ${ }^{15,} 62$ However, for the gas-phase detection and assignment of predominantly surface-bound reactive intermediates, the analyte has to desorb from the catalyst surface. Weakly bound intermediates are in a temperaturedependent equilibrium with the surface and can be volatilized by heating and stabilized in the gas phase by an excess of inert buffer gas. ${ }^{102}$ By electron paramagnetic resonance spectroscopy (EPR), Bährle et al. found radical enhancement during catalytic pyrolysis of lignin, indicative for surface-bound intermediates. ${ }^{103}$ However, no radicals were desorbed from the surface into the gas phase in our guaiacol on HUSY experiments. ${ }^{14}$ Upon exchanging the Brønsted acid proton sites by sodium on HUSY, methyl radicals were clearly detected in the gas phase and transmethylation was suppressed. In addition to unveiling the mechanism of the process, this experiment also showed conclusively that the catalytic process is normally confined to the surface. More strongly bound species can thus be volatilized by changing the surface chemistry. Further methods to consider are laser ablation, selective excitation of the radical-surface bond, as well as attacking it selectively in pulsed operation.

\section{2) Getting all the isomers}

As the number of isomeric and isobaric species increase exponentially with mass, the selectivity of PEPICO and, particularly, PIMS drops for heavier species. When investigating the reaction of phenyl radicals with acrylonitrile:

$\mathrm{C}_{6} \mathrm{H}_{5} \bullet+\mathrm{C}_{3} \mathrm{H}_{3} \mathrm{~N} \rightarrow \mathrm{C}_{9} \mathrm{H}_{8} \mathrm{~N} \bullet \rightarrow \mathrm{C}_{9} \mathrm{H}_{7} \mathrm{~N}+\mathrm{H} \bullet$
Bouwman et al. ${ }^{104}$ showed that PEPICO identification of stable and reactive molecules is easily possible for molecules as large as $\mathrm{C}_{9} \mathrm{H}_{8} \mathrm{~N}\left(\mathrm{~m} / z\right.$ 130). More than $40 \mathrm{C}_{9} \mathrm{H}_{8} \mathrm{~N} \bullet$ radical adducts $(\mathrm{m} / \mathrm{z}$ $130)$ were considered on the potential energy surface of this complex reaction network. Based on ab initio ionization energy calculations and Franck-Condon simulations, it was possible to narrow down the numbers of potential carriers of the $\mathrm{m} / \mathrm{z} 130$ ms-TPES to three radical isomers. ${ }^{104}$ With this achievement in mind, we are convinced that heavier species up to $m / z 150$, and potentially even larger rigid ones with a distinct and isomerspecific vibrational fingerprint, can be unambiguously identified using PEPICO. Such efforts go hand in hand with advanced machine learning algorithms to explore reaction networks and potential energy surfaces to obtain rate information at different conditions, such as the Reaction Mechanism Generator (RGM), ${ }^{105}$ Electronic Structure to Temperature-and PressureDependent Rate Constants (EStokTP), ${ }^{106}$ or KinBot. ${ }^{107}$

\section{3) Detection limits \& quantification}

While sub-ppb detection limits ${ }^{39}$ are reported for conventional photoionization mass spectrometry, conventional photoelectron photoion coincidence methods have a detection limit of 1 ppm at best. ${ }^{108}$ In case of very low conversion, when the reactant dominates the mass spectrum, the detection limit is affected by the dynamic range upon using multiplestart/multiple-stop PEPICO approaches for two particle detection. ${ }^{109}$ Due to the correlation of all photoionization events, electrons and ions originating from separate ionization events, may arrive within the same $\mathrm{m} / \mathrm{z}$ window in the mass spectrum. This false coincidence background leads indeed to a uniform background in the mass spectrum but impedes detection of minor species, when the $\mathrm{m} / \mathrm{z}$ peak of interest becomes commensurate with the Poisson noise of the background. This inherently limits the dynamic range of detection to 1 : 1000 at any photon energy, which can only be improved to 1 : 100'000 by spatial suppression of the false coincidence signal, as recently shown by Osborn and Szataray et al. ${ }^{110}$

Quantification of reactive intermediates in photoionization relies on the mass balance and strategies work well for combustion systems and PEPICO detection. ${ }^{77,78}$ However, their application may be limited in heterogenous systems, depending 
on the amount of adsorbed sample and the desorption rates as pointed out in section 6.1.14

Furthermore, ion imaging (4.1) showed the importance of the reactor alignment with respect to the ionization region, since reactive intermediates may not survive wall collisions and can be quenched. Quantification is thus not only limited by the lack of available ionization cross sections of reactive intermediates which connect the signal intensity to the number density and, thus, to the mole fraction (concentration). However, when cross sections are available, as for the methyl radical ${ }^{61}$ or for formaldehyde, ${ }^{111}$ quantification comes within reach. ${ }^{61}$ This highlights the need for accurate ionization cross sections for reactive molecules, as it allows modelers to validate and develop predictive microkinetic models for catalysis processes.

\section{Conclusions}

We give an overview of the capabilities and analytical dimensions of various gas-phase approaches to detect reactive intermediates and unveil reaction mechanisms in catalysis. We discuss spectroscopies, mass spectrometry with electron and photoionization techniques as well as molecular beam sampling to achieve high sensitivity towards elusive species. Thanks to the tunability of vacuum ultraviolent radiation, provided by synchrotron facilities, isomer-specific detection is possible. In this first analytical dimension, the isomers are separated by their difference in ionization energies using photoionization spectra (see Figure 11). Ethenol, the reactive intermediate in the $\mathrm{Ag} / \mathrm{Al}_{2} \mathrm{O}_{3}$ catalyzed partial oxidation of alcohols, could be distinguished from its tautomer acetaldehyde. In combination with high-resolution mass spectrometers isobaric species, such as propene and ketene can also be separated and the latter species was found to play a role as intermediate in the selective formation of $C_{2}$ to $C_{4}$ species in the Fischer-Tropsch process.

Ion velocity map imaging is introduced as the second analytical dimension (see Figure 11) enabling a direct visualization of the molecular beam emanating from a reactor. As seen in the velocity map images, the sample travels (super)sonically towards the ionization volume after adiabatic expansion with a narrow speed distribution perpendicular to the beam axis. Sampling effects, either due to a misaligned source or significant selective backscattering of sample constituents from the chamber wall, limit or distort radical detection. We show how these effects can be mitigated by ion imaging based on alkane activation by oxyhalogenation.

Fragmentation processes of heavier sample components above their dissociative ionization limit may interfere with radical detection, as they may yield cations with the same molecular mass as the radical of interest. However, some of the excess energy is released as kinetic energy of the fragment ion. We discuss the use of ion velocity map imaging to identify kinetic energy release in molecular beams and separate directly and dissociatively formed ions based on the VMI momentum images.

The isomer-specificity of photoionization spectra is limited because they generally lack sharp spectral features. We introduce photoelectron spectroscopy in coincidence with photoion mass selection as the third analytical dimension to address this limitation (Figure 11). Photoion mass-selected threshold photoelectron spectra (ms-TPES) directly show vibrational transitions from the neutral into the ion, which follow the Franck-Condon principle and can be reliably and routinely simulated for at least the ground electronic state of the ion. Such spectral fingerprints, especially when combined with high-level ionization energy calculations, constitute a sensitive probe of constitutional isomers. The ms-TPES and TPM analysis provided ample mechanistic insight into the noncatalytic decarboxylation resorcinol and the catalytic pyrolysis of guaiacol and helped establish fulvenone ketene as the central reactive intermediate in the latter.

Photoelectron photoion coincidence is shown to be a universal, (isomer-)selective, sensitive, and, thanks to the simultaneous measurement of TPM, multiplexed analytical method. We believe there are numerous future applications, in which these advantages will further be exploited. For instance, isomerselectivity may help us understand the mechanism of semihydrogenation or formation pathways of olefins. Coking is an undesired side-reaction, but, as seen in guaiacol, ${ }^{13}$ it may play a direct role in the process besides deactivating the catalyst and compromising selectivity and conversion. The elementary radical driven coke formation reactions are well understood in the gas phase, ${ }^{112}$ but the addition of a catalyst enables further processes in addition. Lastly, it would be desirable to determine absolute ionization cross sections to quantify reactive intermediates in catalysis processes. This would allow us to deliver reliable kinetic models, benefitting from concepts already applied in combustion models.

\section{Conflicts of interest}

There are no conflicts to declare.

\section{Acknowledgements}

The authors gratefully acknowledge the experimental contributions to the reported experiments from Guido Zichittella, Vladimir Paunovic, Marius Gerlach, Victoria B. F. Custodis and Mathias Steglich. P.H. is funded by Swiss Federal Office of Energy (SFOE, SI/501269-01) and by the Swiss National Science Foundation (SNSF, 200021_178952). A.B. and P.H. thank Patrick Ascher for technical assistance.

\section{References}

1. J. Frenken and I. Groot, in Operando Research in Heterogeneous Catalysis, eds. J. Frenken and I. Groot, Springer, 2017, DOI: DOI: 10.1007/978-3-319-44439$0 \_1$.

2. R. V. Jones, L. Godorhazy, N. Varga, D. Szalay, L. Urge and F. Darvas, J. Comb. Chem., 2006, 8, 110-116.

3. O. Karslıoğlu and H. Bluhm, in Operando Research in Heterogeneous Catalysis, ed. J. F. a. I. Groot, Springer, 2017, DOI: DOI 10.1007/978-3-319-44439-0_2.

4. G. Olivieri, J. B. Giorgi, R. G. Green and M. A. Brown, J. Electron. Spectrosc. Relat. Phenom., 2017, 216, 1-16. 
5. A. Stierle, J. Gustafson and E. Lundgren, in Operando Research in Heterogeneous Catalysis, eds. J. Frenken and I. Groot, 2017, DOI: 10.1007/978-3-31944439-0 3.

6. M. Nachtegaal, U. Hartfelder and J. A. van Bokhoven, in Operando Research in Heterogeneous Catalysis, eds. J. Frenken and I. Groot, 2017, DOI 10.1007/978-3-319-44439-0 4.

7. J. A. van Bokhoven and C. Lamberti, in X-Ray Absorption and X-Ray Emission Spectroscopy, eds. J. A. v. Bokhoven and C. Lamberti, 2016, DOI: 10.1002/9781118844243.fmatter, pp. i-xxii.

8. W. Zhang, S. Xu, X. Han and X. Bao, Chem. Soc. Rev., 2012, 41, 192-210.

9. A. Savara and E. Weitz, Annu. Rev. Phys. Chem., 2014, 65, 249-273.

10. D. B. Rasmussen, J. M. Christensen, B. Temel, F. Studt, P. G. Moses, J. Rossmeisl, A. Riisager and A. D. Jensen, Angew. Chem. Int. Ed., 2015, 54, 7261-7264.

11. Y. Liu, S. Müller, D. Berger, J. Jelic, K. Reuter, M. Tonigold, M. Sanchez-Sanchez and J. A. Lercher, Angew. Chem. Int. Ed., 2016, 55, 5723-5726.

12. C. Wang, Y. Chu, J. Xu, Q. Wang, G. Qi, P. Gao, X. Zhou and F. Deng, Angew. Chem., $2018,130,10354-10358$

13. R. You and W. Huang, ChemCatChem, 2020, DOI: 10.1002/cctc.201901639.

14. P. Hemberger, V. B. F. Custodis, A. Bodi, T. Gerber and J. A. van Bokhoven, Nat. Commun., 2017, 8, 15946

15. V. Paunović, P. Hemberger, A. Bodi, N. López and J. Pérez-Ramírez, Nature Catalysis, 2018, 1, 363-370.

16. A. Beer, Annalen der Physik, 1852, 162, 78-88.

17. J. J. Scherer, J. B. Paul, A. O'Keefe and R. J. Saykally, Chem. Rev., 1997, 97, 25-52.

18. S. Hemdal, A. Johansson, M. Försth, M. Andersson and A. Rosén, Journal of Vacuum Science \& Technology A, 2004, 22, 1620-1624.

19. Å. Johansson, S. Hemdal, M. Andersson and A. Rosén, J. Phys. Chem. A, 2007, 111 6798-6805.

20. E. Fridell, U. Westblom, M. Aldén and A. Rosén, J. Catal., 1991, 128, 92-98.

21. J. Frenken and I. Groot, Operando Research in Heterogeneous Catalysis, 2017.

22. H. Su and E. S. Yeung, J. Am. Chem. Soc., 2000, 122, 7422-7423.

23. S. Blomberg, C. Brackmann, J. Gustafson, M. Aldén, E. Lundgren and J. Zetterberg, ACS Catalysis, 2015, 5, 2028-2034.

24. I. Antonov, K. Voronova, M.-W. Chen, B. Sztáray, P. Hemberger, A. Bodi, D. L. Osborn and L. Sheps, J. Phys. Chem. A, 2019, 123, 5472-5490.

25. G. B. Kistiakowsky and W. P. Slichter, Rev. Sci. Instrum., 1951, 22, 333-337.

26. S. N. Foner and R. L. Hudson, J. Chem. Phys., 1953, 21, 1374-1382.

27. R. Horn, G. Mestl, M. Thiede, F. C. Jentoft, P. M. Schmidt, M. Bewersdorf, R. Weber and R. Schlögl, PCCP, 2004, 6, 4514-4521.

28. R. Horn, K. Ihmann, J. Ihmann, F. C. Jentoft, M. Geske, A. Taha, K. Pelzer and R. Schlög Rev. Sci. Instrum., 2006, 77, 054102.

29. D. W. Kohn, H. Clauberg and P. Chen, Rev. Sci. Instrum., 1992, 63, 4003-4005

30. Q. Guan, K. N. Urness, T. K. Ormond, D. E. David, G. Barney Ellison and J. W. Daily, Int. Rev. Phys. Chem., 2014, 33, 447-487.

31. N. Hansen, T. A. Cool, P. R. Westmoreland and K. Kohse-Höinghaus, Prog. Energy Combust. Sci., 2009, 35, 168-191.

32. A. Winbauer, S. L. Kollmannsberger, C. A. Walenta, P. Schreiber, J. Kiermaier, M. Tschurl and U. Heiz, Anal. Chem., 2016, 88, 5392-5397.

33. A.-P. Elg, M. Andersson and A. Rosén, Appl. Phys. B, 1997, 64, 573-578.

34. L. Luo, R. You, Y. Liu, J. Yang, Y. Zhu, W. Wen, Y. Pan, F. Qi and W. Huang, ACS Catalysis, 2019, 9, 2514-2520.

35. R. M. Garnica, M. F. Appel, L. Eagan, J. R. McKeachie and T. Benter, Anal. Chem., 2000 72, 5639-5646.

36. J. R. Creighton, K. R. Lykke, V. A. Shamamian and B. D. Kay, Appl. Phys. Lett., 1990, $57,279-281$

37. M. Beck, P. Bornhauser, B. Visser, G. Knopp, J. A. van Bokhoven and P. P. Radi, Nat. Commun., 2019, 10, 3270.

38. D. L. Osborn, P. Zou, H. Johnsen, C. C. Hayden, C. A. Taatjes, V. D. Knyazev, S. W. North, D. S. Peterka, M. Ahmed and S. R. Leone, Rev. Sci. Instrum., 2008, 79, 104103.

39. Z. Wen, X. Tang, C. Wang, C. Fittschen, T. Wang, C. Zhang, J. Yang, Y. Pan, F. Liu and W. Zhang, Int. J. Chem. Kinet., 2019, 51, 178-188.

40. C.-Y. Ng, Annu. Rev. Phys. Chem., 2002, 53, 101-140.

41. C. Corder, P. Zhao, J. Bakalis, X. Li, M. D. Kershis, A. R. Muraca, M. G. White and T. K. Allison, Struct. Dyn., 2018, 5, 054301

42. R. Seiler, T. Paul, M. Andrist and F. Merkt, Rev. Sci. Instrum., 2005, 76, 103103.

43. L. Nahon, N. d. Oliveira, G. A. Garcia, J. F. Gil, D. Joyeux, B. Lagarde and F. Polack, Journal of Physics: Conference Series, 2013, 425, 122004

44. A. Bodi, P. Hemberger, D. L. Osborn and B. Sztaray, J. Phys. Chem. Lett., 2013, 4, 2948 2952

45. M. Johnson, A. Bodi, L. Schulz and T. Gerber, Nucl. Instrum. Methods Phys. Res., Sect. A, 2009, 610, 597-603.

46. F. Qi, R. Yang, B. Yang, C. Huang, L. Wei, J. Wang, L. Sheng and Y. Zhang, Rev. Sci. Instrum., 2006, 77, 084101.

47. P. A. Heimann, M. Koike, C. W. Hsu, D. Blank, X. M. Yang, A. G. Suits, Y. T. Lee, M. Evans, C. Y. Ng, C. Flaim and H. A. Padmore, Rev. Sci. Instrum., 1997, 68 1945-1951.

48. G. Meloni, P. Zou, S. J. Klippenstein, M. Ahmed, S. R. Leone, C. A. Taatjes and D. L. Osborn, J. Am. Chem. Soc., 2006, 128, 13559-13567.
49. K. Voronova, K. M. Ervin, K. G. Torma, P. Hemberger, A. Bodi, T. Gerber, D. L. Osborn and B. Sztáray, J. Chem. Phys. Lett., 2018, 9, 534-539.

50. A. B. Attygalle and J. Pavlov, J. Am. Soc. Mass. Spectrom., 2017, 28, 1737-1738.

51. C. A. Taatjes, N. Hansen, A. Mcllroy, J. A. Miller, J. P. Senosiain, S. J. Klippenstein, F. Qi, L. Sheng, Y. Zhang, T. A. Cool, J. Wang, P. R. Westmoreland, M. E. Law, T. Kasper and K. Kohse-Höinghaus, Science, 2005, 308, 1887-1889.

52. Y. Yu, H. He and Q. Feng, J. Phys. Chem. B, 2003, 107, 13090-13092.

53. Y. Li, X. Zhang, H. He, Y. Yu, T. Yuan, Z. Tian, J. Wang and Y. Li, Appl. Catal. B, 2009, 89, 659-664.

54. F. Jiao, J. Li, X. Pan, J. Xiao, H. Li, H. Ma, M. Wei, Y, Pan, Z. Zhou, M. Li, S. Miao, J. Li, Y. Zhu, D. Xiao, T. He, J. Yang, F. Qi, Q. Fu and X. Bao, Science, 2016, 351 , 1065-1068.

55. B. Niu, Y. Bai and D. A. Shirley, J. Chem. Phys., 1993, 99, 2520-2532.

56. P. Masclet, D. Grosjean, G. Mouvier and J. Dubois, J. Electron. Spectrosc. Relat Phenom., 1973, 2, 225-237.

57. A. D. Chowdhury and J. Gascon, Angew. Chem. Int. Ed., 2018, 57, 14982-14985.

58. D. Krüger, P. Oßwald, M. Köhler, P. Hemberger, T. Bierkandt and T. Kasper, Proc. Combust. Inst., 2019, 37, 1563-1570.

59. B. Sztáray, K. Voronova, K. G. Torma, K. J. Covert, A. Bodi, P. Hemberger, T. Gerber and D. L. Osborn, J. Chem. Phys., 2017, 147, 013944.

60. D. W. Chandler and P. L. Houston, J. Chem. Phys., 1987, 87, 1445-1447.

61. V. Paunović, G. Zichittella, P. Hemberger, A. Bodi and J. Pérez-Ramírez, ACS Catalysis, 2019, 9, 1710-1725.

62. G. Zichittella, M. Scharfe, B. Puértolas, V. Paunović, P. Hemberger, A. Bodi, L. Szentmiklósi, N. López and J. Pérez-Ramírez, Angew. Chem. Int. Ed., 2019, 58, 5877-5881.

63. G. Zichittella, P. Hemberger, F. Holzmeier, A. Bodi and J. Pérez-Ramírez, J. Chem. Phys. Lett., 2020, DOI: 10.1021/acs.jpclett.9b03836, 856-863.

64. B. Sztáray, A. Bodi and T. Baer, J. Mass Spectrom., 2010, 45, 1233-1245.

65. B. E. Miller and T. Baer, Chem. Phys., 1984, 85, 39-45.

66. T. Baer, A. Bodi and B. Sztáray, in Encyclopedia of Spectroscopy and Spectrometry (Third Edition), eds. J. C. Lindon, G. E. Tranter and D. W. Koppenaal, Academic Press, Oxford, 2017, DOI: https://doi.org/10.1016/B978-0-12 409547-2.11311-3, pp. 635-649.

67. S. Borkar and B. Sztáray, J. Phys. Chem. A, 2010, 114, 6117-6123.

68. T. Baer and R. P. Tuckett, PCCP, 2017, 19, 9698-9723.

69. A. K. Vasiliou, K. M. Piech, B. Reed, X. Zhang, M. R. Nimlos, M. Ahmed, A. Golan, O. Kostko, D. L. Osborn, D. E. David, K. N. Urness, J. W. Daily, J. F. Stanton and G. B. Ellison, J. Chem. Phys., 2012, 137, 164308.

70. P. Hemberger, A. J. Trevitt, T. Gerber, E. Ross and G. da Silva, J. Phys. Chem. A, 2014, 118, 3593-3604.

71. P. Hemberger, A. J. Trevitt, E. Ross and G. da Silva, J. Chem. Phys. Lett., 2013, 4, 2546 2550.

72. M. Steglich, V. B. F. Custodis, A. J. Trevitt, G. daSilva, A. Bodi and P. Hemberger, J. Am. Chem. Soc., 2017, 139, 14348-14351.

73. J. M. Dyke, $P C C P, 2019,21,9106-9136$.

74. K. Majer, R. Signorell, M. F. Heringa, M. Goldmann, P. Hemberger and A. Bodi, Chem. Eur. J., 2019, 25, 14192-14204.

75. B. K. Cunha de Miranda, C. Alcaraz, M. Elhanine, B. Noller, P. Hemberger, I. Fischer, G. A. Garcia, H. Soldi-Lose, B. Gans, L. A. Mendes, S. Boye-Peronne, S. Douin, J. Zabka and P. Botschwina, J. Phys. Chem. A, 2010, 114, 4818-4830.

76. V. B. F. Custodis, P. Hemberger, Z. Ma and J. A. van Bokhoven, J. Phys. Chem. B, 2014 $118,8524-8531$.

77. P. Oßwald, P. Hemberger, T. Bierkandt, E. Akyildiz, M. Köhler, A. Bodi, T. Gerber and T. Kasper, Rev. Sci. Instrum., 2014, 85, 025101.

78. J. Krüger, G. A. Garcia, D. Felsmann, K. Moshammer, A. Lackner, A. Brockhinke, L. Nahon and K. Kohse-Höinghaus, PCCP, 2014, 16, 22791-22804.

79. D. Schleier, P. Constantinidis, N. Faßheber, I. Fischer, G. Friedrichs, P. Hemberger, E. Reusch, B. Sztáray and K. Voronova, PCCP, 2018, 20, 10721-10731.

80. T. Koopmans, Physica, 1934, 1, 104-113.

81. T. Gerber, Y. Liu, G. Knopp, P. Hemberger, A. Bodi, P. Radi and Y. Sych, Rev. Sci. Instrum., 2013, 84, 033101.

82. F. Holzmeier, M. Lang, I. Fischer, P. Hemberger, G. A. Garcia, X. Tang and J. C. Loison, PCCP, 2015, 17, 19507-19514.

83. D. V. Chicharro, S. M. Poullain, L. Bañares, H. R. Hrodmarsson, G. A. García and J.-C. Loison, PCCP, 2019, 21, 12763-12766.

84. M. Lang, F. Holzmeier, P. Hemberger and I. Fischer, J. Phys. Chem. A, 2015, 119, 39954000.

85. P. Hemberger, M. Lang, B. Noller, I. Fischer, C. Alcaraz, B. K. Cunha de Miranda, G. A Garcia and H. Soldi-Lose, J. Phys. Chem. A, 2011, 115, 2225-2230.

86. T. Schüßler, H.-J. Deyerl, S. Dümmler, I. Fischer, C. Alcaraz and M. Elhanine, J. Chem Phys., 2003, 118, 9077-9080.

87. J. D. Savee, J. Zádor, P. Hemberger, B. Sztáray, A. Bodi and D. L. Osborn, Mol. Phys. $2015,113,2217-2227$

88. E. Reusch, F. Holzmeier, P. Constantinidis, P. Hemberger and I. Fischer, Angew. Chem., 2017, 129, 8113-8116.

89. H. R. Hrodmarsson, G. A. Garcia, L. Nahon, B. Gans and J.-C. Loison, J. Phys. Chem. A 2019, 123, 9193-9198.

90. Z. Ma, E. Troussard and J. A. van Bokhoven, Applied Catalysis A: General, 2012, 423 424, 130-136. 
91. R. H. Venderbosch, ChemSusChem, 2015, 8, 1306-1316.

92. A. K. Vasiliou, J. H. Kim, T. K. Ormond, K. M. Piech, K. N. Urness, A. M. Scheer, D. J. Robichaud, C. Mukarakate, M. R. Nimlos, J. W. Daily, Q. Guan, H.-H. Carstensen and G. B. Ellison, J. Chem. Phys., 2013, 139, 104310.

93. A. M. Scheer, C. Mukarakate, D. J. Robichaud, M. R. Nimlos, H.-H. Carstensen and G. B. Ellison, J. Chem. Phys., 2012, 136, 044309.

94. A. M. Scheer, C. Mukarakate, D. J. Robichaud, M. R. Nimlos and G. B. Ellison, J. Phys. Chem. A, 2011, 115, 13381-13389.

95. D. J. Robichaud, A. M. Scheer, C. Mukarakate, T. K. Ormond, G. T. Buckingham, G. B. Ellison and M. R. Nimlos, J. Chem. Phys., 2014, 140, 234302.

96. V. B. F. Custodis, P. Hemberger and J. A. van Bokhoven, Chem. Eur. J., 2017, 23, 86588668.

97. T. K. Ormond, J. H. Baraban, J. P. Porterfield, A. M. Scheer, P. Hemberger, T. P. Troy, M. Ahmed, M. R. Nimlos, D. J. Robichaud, J. W. Daily and G. B. Ellison, J. Phys. Chem. A, 2018, 122, 5911-5924.

98. M. Gerlach, A. Bodi and P. Hemberger, PCCP, 2019, 21, 19480-19487.

99. Y. Furutani, S. Kudo, J.-i. Hayashi and K. Norinaga, J. Phys. Chem. A, 2017, 121, 631637.

100. R. Fushimi and J. Gleaves, Current Opinion in Chemical Engineering, 2018, 21, 10-21.

101. K. Morgan, N. Maguire, R. Fushimi, J. T. Gleaves, A. Goguet, M. P. Harold, E. V. Kondratenko, U. Menon, Y. Schuurman and G. S. Yablonsky, Catalysis Science \& Technology, 2017, 7, 2416-2439.

102. S. Feng, X. Lin, X. Song, Y. Liu, Z. Jiang, P. Hemberger, A. Bodi and Y. Ding, J. Catal., 2020, 381, 193-203.

103. C. Bährle, V. Custodis, G. Jeschke, J. A. van Bokhoven and F. Vogel, ChemSusChem, 2016, 9, 2397-2403.

104. J. Bouwman, A. Bodi and P. Hemberger, PCCP, 2018, 20, 29910-29917.

105. C. W. Gao, J. W. Allen, W. H. Green and R. H. West, Comput. Phys. Commun., 2016 203, 212-225.

106. C. Cavallotti, M. Pelucchi, Y. Georgievskii and S. J. Klippenstein, Journal of Chemical Theory and Computation, 2019, 15, 1122-1145.

107. R. Van de Vijver and J. Zádor, Comput. Phys. Commun., 2019, DOI: https://doi.org/10.1016/j.cpc.2019.106947, 106947.

108. T. Bierkandt, P. Hemberger, P. Oßwald, M. Köhler and T. Kasper, Proc. Combust. Inst., 2017, 36, 1223-1232.

109. A. Bodi, B. Sztáray, T. Baer, M. Johnson and T. Gerber, Rev. Sci. Instrum., 2007, 78, 084102.

110. D. L. Osborn, C. C. Hayden, P. Hemberger, A. Bodi, K. Voronova and B. Sztáray, J. Chem. Phys., 2016, 145, 164202.

111. W. Wen, S. Yu, C. Zhou, H. Ma, Z. Zhou, C. Cao, J. Yang, M. Xu, F. Qi, G. Zhang and Y. Pan, Angew. Chem. Int. Ed., n/a.

112. D. S. N. Parker, R. I. Kaiser, T. P. Troy and M. Ahmed, Angew. Chem. Int. Ed., 2014, $53,7740-7744$. 